\title{
LA ESCUELA NUEVA EN IMÁGENES: FOTOGRAFÍA Y PROPAGANDA EN THE NEW ERA (1920-1939)**
}

\author{
Picturing the Progressive Education: \\ Images and Propaganda in The New Era (1920-1939)
}

\section{Sjaak Braster ${ }^{\S}$ y María del Mar del Pozo Andrés ${ }^{\dagger}$}

Fecha de recepción: 11/02/2018 • Fecha de aceptación: 11/03/2018

Resumen. En este artículo se aborda la labor de propaganda sobre el movimiento de la Escuela Nueva que realizó The New Era, la revista en lengua inglesa que fue pionera, pues comenzó a publicarse en 1920, y también la primera que se erigió en órgano de expresión de la New Education Fellowship, la organización que aglutinó a los educadores de todo el mundo que compartían las ideas innovadoras del movimiento.

Esta labor de propaganda se ha estudiado a partir de las imágenes que la revista publicó entre 1920 y 1939. A través de una metodología que combina el análisis de contenido y la grounded theory identificamos una serie de categorías que relacionamos con los grandes ideales de la Escuela Nueva. Consideramos, como punto de partida, que aquellas ideas y prácticas escolares que la revista visibilizó más —es decir, de las que publicó más imágenes- fueron aquellas con las que pretendía construir en la opinión pública un imaginario de la Escuela Nueva.

Las seis ideas en torno a las que hemos organizado el discurso visual construido por esta revista son: coeducación, actividad, libertad, contacto con la naturaleza, paidocentrismo, e individualización vs socialización. De cada una de ellas hemos cuantificado el número de imágenes que se publicaron, diferenciadas por países y por períodos temporales. A partir del análisis cuantitativo, hemos tratado de explicar las pautas generales y los rasgos excepcionales, para concluir presentando las características más

\footnotetext{
* Este artículo ha sido posible gracias a la financiación concedida al proyecto I+D «La fotografía escolar en colecciones documentales de ámbito estatal (1900-1970)» [EDU2014-52498-C2-1-P], subvencionado por el Ministerio de Economía y Competitividad.

$\S$ Department Public Administration and Sociology, Erasmus School of Social and Behavioural Sciences, Erasmus University Rotterdam. PO Box 1738, 3000 DR Rotterdam. Países Bajos. braster@ essb.eur.nl

† Departmento de Ciencias de la Educación. Facultad de Educación. Universidad de Alcalá., Aulario María de Guzmán, c/ San Cirilo, s/n, 28801 Alcalá de Henares. España. mar.pozo@uah.es
}

Cómo citar este artículo: Braster, Sjaak y María del Mar Pozo Andrés. «La Escuela Nueva en Imágenes: Fotografía y Propaganda en The New Era (1920-1939)». Historia y Memoria de la Educación 8 (2018): 97-145. 
destacables del discurso iconográfico sobre la Nueva Educación que construyó y divulgó The New Era.

Palabras clave: Escuela Nueva; The New Era; Propaganda pedagógica; Fotografía

Abstract. In this article we analyse the propaganda work done by the journal The New Era for divulgating and popularising the progressive education movement. The review started in 1920, so it was the first in transmitting the ideas of this movement, and also the first English language journal that became the channel of expression of the New Education Fellowship, for divulgating the innovative ideals in the Anglo-saxon countries.

We have studied the propaganda work from the images that the journal has published between 1920 and 1939. As a research method we have chosen a combination of content analysis and a grounded theory approach. We have identified a list of categories that are connected with the characteristics of new or progressive education. We have considered as starting point that all the ideals and school practices made more visible by the journal, i.e., the ones that were shown in many images, were those used for building a public image of the New Education.

We have organized the visual discourse built by The New Era around six ideas: coeducation, activity, freedom, nature, child-centered, and individualization versus socialization. We have quantified the number of images that were published in connexion with everyone of these ideas, making comparisons between spaces and times. The quantitative analysis has allowed us to explain general patterns and exceptional features. Finally, we present the most remarkable characteristics of the iconographical discourse about the New Education that was built and propagated by The New Era.

Key Words: Progressive Education; The New Era; Pedagogical propaganda; Photography

\section{INTRODUCCIÓN: PROPAGANDA PEDAGÓGICA Y ESCUELA NUEVA}

La inclusión en un título del término "propaganda» suele ser una apuesta arriesgada, porque posiciona al lector, a priori, sobre el contenido del texto, que presupone narrará algún acontecimiento histórico en el que se intentó manipular a las masas para dirigirlas en unas determinadas líneas políticas e ideológicas, utilizando técnicas que, como mínimo, ocultaron o falsearon la información. Este posicionamiento inicial es debido a las connotaciones negativas que la palabra «propaganda» empezó a tener después de la Primera Guerra Mundial; y ese significa- 
do desfavorable no hizo sino aumentar al acabar la Segunda, cuando se fueron conociendo las tropelías que los jerifaltes nazis habían realizado y clasificado como propagandísticas.

Sin embargo, este concepto tuvo un significado bastante neutral hasta finales del siglo XIX, que se derivaba de su etimología latina, y que se entendía como la propagación de una doctrina o práctica determinadas. Con este sentido, por ejemplo, introdujeron los institucionistas ${ }^{1}$ españoles el término "propaganda pedagógica» al menos desde 1894, dándole incluso un carácter de movimiento en 1913, con el que se pretendía llevar a cabo una amplia campaña de divulgación educativa para concienciar a la opinión pública sobre los problemas de enseñanza y ganarse su apoyo para comenzar la tarea de renovar culturalmente España desde arriba. ${ }^{2}$

La I Guerra Mundial introdujo un nuevo concepto de propaganda, en el que la imagen visual se utilizó como medio de comunicación de mensajes persuasivos a través de nuevos soportes tecnológicos, como el cine o el cartelismo político. También fue el primer escenario en el que se emplearon técnicas modernas, recogidas de las Ciencias Sociales, de control de la opinión pública, especialmente por parte de los aliados. La comprensión, acabada la guerra, de los mecanismos de manipulación utilizados por los gobiernos, unida a la práctica sistemática de denominar "propaganda» a las comunicaciones enemigas, hicieron que el término adquiriese un significado negativo, que aún se endureció mucho más después de su asociación con las prácticas despóticas de los regímenes stalinista y nazi. ${ }^{3}$

Es justamente en los años veinte cuando algunos publicistas pioneros intentaron encarrilar el concepto por sus tradicionales derroteros neutrales, insistiendo mucho en una definición muy cercana a la de información, de manera que caracterizaron a la propaganda como un mecanismo de diseminación de ideas a gran escala, como un esfuerzo organizado de divulgar creencias y doctrinas particulares. En esta línea, Edward Louis

\footnotetext{
${ }^{1}$ Denominamos institucionistas a aquellas personas afines a la Institución Libre de Enseñanza.

${ }^{2}$ Rafael Altamira, Exigencias de la propaganda pedagógica (Madrid: Tipografía «La Itálica», 1913) y Rafael María de Labra, Discurso pronunciado el día 11 de noviembre de 1913 en el Ateneo de Madrid, con motivo de la apertura de las Cátedras (Madrid: Est. Tip. de Fortanet, 1913), 6-9.

${ }^{3}$ Colin Moore, Propaganda Prints. A History of Art in the Service of Social and Political Change (London: A\&C Black Publishers Limited, 2010), 7-8, y Stanley Newcourt-Nowodworski, La propaganda negra en la Segunda Guerra Mundial (Barcelona: Algaba Ediciones, 2006).
} 
Bernays, un austriaco sobrino de Freud y a quien se considera inventor de la teoría de la propaganda, razonó en su obra seminal, publicada en 1928, que denominaba «moderna propaganda» a la práctica de crear imágenes en las mentes de millones de personas para conectarlas con una idea, empresa o grupo, y que la legitimidad de este esfuerzo venía marcada por el valor de la obra que se quería difundir y por la corrección de la información utilizada en su difusión. ${ }^{4}$

En este contexto de descubrimiento de la opinión pública, el primer interrogante de este artículo es averiguar si los protagonistas del movimiento pedagógico mundial surgido en los años veinte, el que en España denominamos Escuela Nueva y que en los países anglosajones se conoció como «New Education» o "Progressive Education», fueron conscientes de la importancia de utilizar las modernas técnicas propagandísticas para difundir sus mensajes pedagógicos a gran escala. Es prácticamente un interrogante retórico, pues la abundante literatura publicada en los últimos años sobre este movimiento con propósitos desmitificadores muestra la vocación propagandística de sus primeras y más conocidas figuras. El hecho de que Maria Montessori ya impulsase películas documentales sobre sus métodos, que presentó ante grandes audiencias en Gran Bretaña y Estados Unidos a comienzos de los años diez, ${ }^{5}$ y el hecho de que su ejemplo fuera seguido por Decroly ${ }^{6}$ y por muchos otros en los años veinte, justifican la afirmación de Ferrière de que «les films d'Éducation nouvelle ont foisonné» en todos los Congresos Internacionales de Educación Nueva desde 1929.7

Como es bien sabido, la Escuela Nueva fue un movimiento transnacional, impulsado a partir de la celebración del primer Congreso Internacional de Educación Nueva en Calais (1921), ${ }^{8}$ durante el cual se produjo

\footnotetext{
${ }^{4}$ Edgard L. Bernays, Propaganda (New York: Horace Liveright, 1928), 20-25.

${ }^{5}$ Gerald L. Gutek y Patricia A. Gutek, Bringing Montessori to America. S.S. McClure, Maria Montessori and the Campaign to Publicize Montessori Education (Tuscaloosa: The University of Alabama Press, 2016), 132 y 141.

${ }^{6}$ Angelo Van Gorp, «The Decroly School in documentaries (1930s-1950s): contextualising propaganda from within», Paedagogica Historica 47, no. 4 (2011): 507-523.

${ }^{7}$ Adolphe Ferrière, «La formation des Maîtres à l'aide du cinéma», Pour l'Ère Nouvelle XIII, no. 100 (1934): 197.

${ }^{8}$ Jean-François Condette y Antoine Savoye, «Une éducation pour l'ère nouvelle, le congrès international d'éducation de Calais 1921», Études Sociales 163 (2016): 43-79.
} 
la creación de la New Education Fellowship (NEF), que fue el network en el que se integraron aquellos educadores que creían en una educación centrada en la personalidad infantil. ${ }^{9}$ En su fundación intervinieron tres figuras, el suizo Adolphe Ferrière, la alemana Elizabeth Rotten y la británica Beatrice Ensor. Esta última aportó las raíces institucionales de la NEF, la Theosophical Fraternity in Education que había contribuido a establecer en 1915, en medio del horror de la I Guerra Mundial, llevada por la idea de que el conflicto bélico hubiera podido evitarse con una educación diferente. ${ }^{10}$ Ensor pensaba que la nueva educación podía cambiar el mundo, pero no con medidas legislativas, sino "changing public opinion and the hearts and minds of men and women", ${ }^{11}$ es decir, con una acción de propaganda tal y como la entendían los intelectuales de la posguerra.

A Ensor se la identificó en su país como una «super woman» entregada a realizar el «propaganda work» de la NEF, que se entendía como «to spread ideals in teaching that would make future hostilities unthinkable». Muchas fueron las actividades propagandísticas —entendidas como de divulgación pedagógica entre la opinión pública y entre los profesionales de la educación- que Beatrice Ensor realizó a lo largo de su vida; entre

\footnotetext{
${ }^{9}$ Celia M. Jenkins, «The professional middle class and the social origins of progressivism: A case study of the New Education Fellowship, 1920-1950» (Tesis doctoral, Universidad de Londres, 1989); Celia Jenkins, «New Education and its emancipatory interests (1920 - 1950)», History of Education 29, no 2 (2000): 139-151; Margaret H. White, «The New Education Fellowship: An international community of practice», New Era in Education 82, no. 3 (2001): 71-75; Kevin J. Brehony, «From the particular to the general, the continuous to the discontinuous: progressive education revisited», History of Education 30, no. 5 (2001): 413-432; Kevin J. Brehony, «A New Education for a New Era: The Contribution of the Conferences of the New Education Fellowship to the Disciplinary Field of Education 1921-1938», Paedagogica Historica 40, no. 5-6 (2004): 733-755; Laurent Gutierrez, «La Ligue Internationale pour l'Éducation Nouvelle. Contribution à l'histoire d'un mouvement international de réforme de l'enseignement (1921-1939)", Spirale - Revue de Recherches en Éducation 45 (2009): 29-41 y Joseph Watras, «The New Education Fellowship and UNESCO's programme of fundamental education», Paedagogica Historica 47, no. 1-2 (2011): 191-205.

${ }^{10}$ Sylvain Wagnon, «Les théosophes et l'organisation internationale de l'éducation nouvelle (19111921)», REHMLAC+ 9, no. 1 (2017): 146-180; Sue C. Middleton, «New Zealand Theosophists in "New Education" networks, 1880s-1938», History of Education Review 46, no. 1 (2017): 42-57, y Maxwell D. Lawson, «The New Education Fellowship: The Formative Years», Journal of Educational Administration and History 13, no. 2 (1981): 24-28. Beatrice Ensor identificaba de tal manera la Theosophical Fraternity in Education con la NEF que, en 1937, durante la sesión inaugural de su VII Congreso, celebrado en Cheltenham (Gran Bretaña), afirmó sin ambages que fundó la NEF en 1915, en medio de la Gran Guerra, inspirada sobre todo por el deseo de encontrar nuevos métodos para prevenir conflictos en el futuro. «Seventh World Conference of New Education Fellowship», Cheltenham Chronicle and Gloucestershire Graphic, 8 de Agosto de 1936.

${ }^{11}$ «Education Ideals. Lecture to Teachers at Portsmouth», Portsmouth Evening News, 17 de Noviembre de 1921.
} 
ellas su trabajo como conferenciante y embajadora de la Escuela Nueva en diversas partes del mundo, su papel como organizadora del «educational tourist traffic», ${ }^{12}$ y su participación en los congresos bianuales de la NEF. ${ }^{13}$

Sin embargo, su gran aportación fue la publicación de la revista The New Era desde enero de 1920, como órgano de expresión de la Theosophical Fraternity. Cuando se creó la NEF en julio de 1921, Ensor cedió su magazine para la divulgación del movimiento de la Escuela Nueva en los países de lengua inglesa. Esta publicación sirvió de ejemplo para la versión en lengua francesa, Pour l'Ère Nouvelle, que vio la luz en enero de 1922, dirigida por Adolphe Ferrière; y para la versión en alemán, Das Werdende Zeitalter, editada, también desde 1922, por Elisabeth Rotten. Estas tres revistas se convirtieron en las fuentes principales de divulgación del movimiento de la Escuela Nueva ante las audiencias europeas de educadores e interesados; además, sus suscriptores se convertían automáticamente en miembros de la NEF. Edward Bernays señaló en 1928 que las reuniones públicas ya no eran unos mecanismos de propaganda tan eficaces como cincuenta años antes; sin embargo, las revistas le parecían un medio ideal, porque podían seleccionar su material deliberadamente, «in accordance with a continuous policy», y por eso "tends rather to become a propagandist organ, propagandizing for a particular idea». ${ }^{14}$ Desde luego, en la abundante literatura existente sobre Pour l'Ėre Nouvelle se ha subrayado con frecuencia su carácter militante y propagandístico. ${ }^{15}$ Con ese mismo "propagandist character» definió la propia Beatrice Ensor a su revista, The New Era, en 1934, aunque evidentemente le daba un significado muy particular a la expresión, pues ligaba este rasgo al escaso número de suscriptores. ${ }^{16}$ Das Werdende Zeitalter se vio obligada a

\footnotetext{
12 «She Pulls the Strings» y «Plans for Professors», Birmingham Daily Gazette, 19 de Julio de 1932.

${ }^{13}$ Brehony, «A new education for a new era», 733-755.

${ }^{14}$ Bernays, Propaganda, 153.

${ }^{15}$ Daniel Hameline, «Les premières années de Pour l'Ėre nouvelle: militantisme et propagande?», Les Sciences de l'éducation - Pour l'Ère nouvelle 35, no. 4 (2002): 34-35. Ver también, Béatrice Haenggeli-Jenni, «Pour l'Ère Nouvelle: une revue carrefour entre science et militance (1922-1940)» (Tesis doctoral, Universidad de Ginebra, 2011); Béatrice Haenggeli-Jenni, «"Savoirs” constitués et programmes scolaires: débats au cœur de la revue Pour l'Ère Nouvelle (1922-1940)", Recherches \& Éducations 4 (2011): 13-25; y Béatrice Haenggeli-Jenni y Rita Hofstetter, «Pour l'Ėre Nouvelle (1922-1940). La science convoquée pour fonder une "Internationale de l'Éducation" ", Carrefours de l'Éducation 31 (2011): 137-159.

${ }^{16}$ Steffi Koslowski, Die New Era der New Education Fellowship: Ihr Beitrag zur Internationalität der Reformpädagogik in 20. Jahrhundert (Bad Heilbrunn: Julius Klinkhardt, 2013), 159.
} 
desaparecer en 1932, porque sus contenidos chocaban frontalmente con los mensajes que imponían ese gran propagandista que era el régimen nacional-socialista. ${ }^{17}$

Este artículo pretende estudiar el corpus pedagógico que divulgó uno de los tres órganos de expresión del movimiento de la Escuela Nueva, The New Era, pero analizando exclusivamente su acervo de imágenes. Es decir, intentamos descubrir cómo se representaron iconográficamente los treinta principios de la Nueva Educación que Ferríère presentó con una estructura enumerativa propia de una narrativa convencional, ${ }^{18}$ para detectar los aspectos del discurso lingüístico que se visibilizaron o se invisibilizaron en el discurso visual. Partimos de la hipótesis inicial de que aquellas prácticas escolares que la revista visibilizó más fueron aquellas con las que pretendía construir en la opinión pública un imaginario de la Nueva Educación.

La historiografía educativa reciente ha mostrado gran interés por analizar los registros iconográficos del movimiento de la Escuela Nueva. Joseph Coquoz demostró cómo sus representantes utilizaron las imágenes muy conscientemente para representar la ruptura con la denominada "escuela tradicional». ${ }^{19}$ Francisca Comas y Bernat Sureda concluyeron que los enfoques metodológicos innovadores ensayaron su propia iconografía, así como una nueva gramática gráfica. En ella se mostraba un imaginario concentrado en los aspectos de la autonomía infantil, la capacidad del niño para aprender y asimilar valores sin presiones externas, la libertad como una herramienta educativa fundamental, la importancia del ejercicio físico y el juego y la intervención discreta del maestro. ${ }^{20} \mathrm{Ca}$ therine Burke y Ian Grosvenor mencionaron cinco elementos definitorios de la que caracterizaron como «the progressive image in the history of education»: posición marginal del maestro, niño solo y concentrado, cuerpos con variedad de expresiones y en movimiento, infancia produc-

\footnotetext{
${ }^{17}$ Dietmar Haubfleisch y Jörg-Werner Link (eds.), Das Werdende Zeitalter (Internationale Erziehungs-Rundschau) (Bonn: Archiv der Arbeiterjugendbewegung, 1994).

${ }^{18}$ Adolphe Ferrière, «L'école nouvelle et le Bureau international des Écoles nouvelles», Pour l'Ère Nouvelle 4, no. 15 (1925): 2-8.

${ }^{19}$ Joseph Coquoz, «Un modèle suisse "d'École active” durant l'entre-deux-guerres: images et mirages», Paedagogica Historica 36, no. 1 (2000): 369-388.

${ }^{20}$ Francisca Comas Rubí y Bernat Sureda García, «The photography and propaganda of the Maria Montessori method in Spain (1911-1931)», Paedagogica Historica 48, no. 4 (2012): 571-587.
} 
tora de arte, y actividades de talleres en entornos grupales. ${ }^{21}$ Richard Aldrich, encontró tres rasgos propios de los planteamientos paidocéntricos en la educación británica: ubicación de las escuelas; uso de los espacios abiertos y utilización de métodos activos de enseñanza y aprendizaje en los que se combinaba el trabajo individual y en grupo. ${ }^{22}$

En el único trabajo existente hasta la fecha sobre The New Era se incluye un breve acercamiento iconográfico, abogándose por la necesidad de realizar en el futuro un análisis serial de todas las imágenes publicadas. ${ }^{23}$ Éste es precisamente el enfoque metodológico que hemos escogido en este artículo, por creerlo el más adecuado para responder a los interrogantes planteados.

\section{MÉTODOS DE ANÁLISIS DE IMÁGENES EN THE NEW ERA}

Las tres revistas que se convirtieron en los órganos de expresión de la NEF fueron los instrumentos más consistentes y persistentes para propagar las ideas pedagógicas del movimiento de la Escuela Nueva. La versión francesa, Pour l'Ère Nouvelle, a pesar de su larga trayectoria (1922-1947), quedó fuera de nuestro estudio porque apenas incluyó imágenes en ningún momento de su historia. La versión alemana, Das Werdende Zeitalter, sí que recogió una selección representativa de dibujos y fotografías, pero sólo se publicó en la década 1922-1932, una etapa muy corta, lo que impide realizar un análisis serial en un periodo continuado. La versión inglesa, cuyo título completo en sus orígenes fue Education for the new era. An international quarterly magazine for the promotion and reconstruction in education, se constituyó en la fuente que nos permitía responder al interrogante planteado en esta investigación.

El periodo analizado, desde el primer número de enero de 1920 hasta el de diciembre de 1939, que marcó el comienzo de la II Guerra Mundial, abarca veinte años, lo que nos posibilitó establecer dos ejes comparati-

\footnotetext{
${ }^{21}$ Catherine Burke y Ian Grosvenor, «The Progressive Image in the History of Education: Stories of Two Schools», Visual Studies 22, no. 2 (2007): 159-163.

${ }^{22}$ Richard Aldrich, «The Plowden report, 1967: A visual study in primary school location, space and learning». Comunicación presentada en ISCHE XX, Universidad de Lovaina, Bélgica, 1998.

${ }^{23}$ Koslowski, Die New Era, 285-292.
} 
vos: el tiempo, buscando diferencias entre las décadas de los años veinte y los años treinta; y los espacios, pues las fotografías publicadas no se circunscribían solamente a Gran Bretaña, sino que incluían Estados Unidos, Francia, Alemania y muchos otros países, entre ellos España, bien que con una representación casi testimonial. Nuestra base de datos se construyó a partir de todas las imágenes aparecidas en los veinte volúmenes de la revista, un total de 944, de las cuales excluimos, conscientemente, un grupo muy escaso y frecuentemente repetido de ilustraciones de edificios escolares que acompañaban los anuncios publicitarios de internados y colegios privados considerados como escuelas nuevas. El contexto de las imágenes se reconstruyó a partir de los pies y leyendas explicativas, y de los diálogos establecidos con los textos de los artículos en los que se insertaron la mayoría de las fotografías.

El método de investigación elegido para estudiar el archivo visual así construido fue una combinación de análisis de contenido ${ }^{24} \mathrm{y}$ de grounded theory ${ }^{25}$ —enfoque traducido al castellano, de forma muy inadecuada a nuestro parecer, como «teoría fundamentada»-. El análisis de contenido es una técnica que se utiliza habitualmente para estudiar imágenes, ${ }^{26}$ siendo especialmente apropiada para trabajar con largas series iconográficas. A continuación, enumeraremos y describiremos los pasos que hemos seguido para analizar nuestra base de datos visual:

1) Localización y acceso a todos los números de The New Era de los años 1920-1939. La colección completa puede consultarse en el archivo y la biblioteca del Institute of Education de Londres. Revisamos también la misma colección en la Koninklijke Bibliotheek de La Haya, a partir de la primera fecha disponible, enero de 1923, pues las facilidades de publicación de imágenes en esta segunda institución eran considerablemente más generosas.

\footnotetext{
${ }^{24}$ Klaus Krippendorf, Content analysis: An introduction to its methodology (London: Sage, 2004).

${ }^{25}$ Anselm Strauss y Juliet M. Corbin, «Grounded theory methodology: An overview», en Handbook of qualitative research, eds. Norman K. Denzin e Yvonna S. Lincoln (Thousand Oaks: Sage, 1994), 273-285.

${ }^{26}$ Philip Bell, «Content analysis of visual images», en Handbook of visual analysis, eds. Theo Van Leeuwen y Carey Jewitt (London: Sage, 2001), 10-34; Annekatrin Bock, Holger Iserman y Thomas Knieper, «Quantitative content analysis of the visual», en The Sage Handbook of visual research methods, eds. Eric Margolis y Luc Pauwels (London: Sage, 2011), 265-282, y Gillian Rose, Visual methodologies: An introduction to researching with visual materials (London: Sage, 20164).
} 
2) Realización de fotografías de todas las imágenes, incluyendo sus títulos, pies y leyendas u otros fragmentos textuales relevantes. El número de imágenes recopiladas fue de 944; el de páginas fotografiadas con imágenes y texto fue de 1064 .

3) Descripción de todas las imágenes con palabras clave inspiradas por los treinta principios de la Escuela Nueva enunciados por Ferrière (códigos abiertos).

4) Introducción de todos los códigos abiertos en un archivo de datos SPSS, etiquetándolos de acuerdo con tres variables nominales que denominamos contenido, pie de foto y contexto.

5) Comparación constante de los códigos abiertos para llegar a establecer un conjunto limitado de códigos axiales.

6) Entrada de todos los códigos axiales como variables nominales en nuestro archivo de datos SPSS.

7) Análisis de las relaciones bivariadas entre las variables nominales en unas tablas cruzadas, incluyendo el cálculo del nivel de significación estadística de esas relaciones con las pruebas Chi-cuadrado.

8) Establecimiento de las relaciones multivariantes entre las variables nominales mediante un análisis de correspondencia múltiple. ${ }^{27}$ Éste fue realizado usando el programa estadístico HOMALS, desarrollado por el Departamento de Teoría de Datos de la Universidad de Leiden (Países Bajos). ${ }^{28}$

La codificación abierta y la codificación axial nos permitió establecer la siguiente lista de variables nominales:

1) Género, con las categorías: (a) un niño solo; (b) una niña sola; (c) varios niños; (d) varias niñas; (e) mezcla de sexos.

2) Desnudez, con las categorías: (a) al menos un niño/a completamente desnudo; (b) al menos un niño/a con los pies, el pecho y/o las extre-

\footnotetext{
${ }^{27}$ Se ha utilizado esta técnica para descubrir pautas entre códigos ligados con imágenes en los siguientes artículos: Sjaak Braster, «Educational change and Dutch classroom photographs: A qualitative and quantitative analysis», en The Black Box of Schooling. A Cultural History of the Classroom, eds. Sjaak Braster, Ian Grosvenor y María del Mar del Pozo Andrés (Brussels: Peter Lang, 2011), 21-37, y Sjaak Braster y María del Mar del Pozo Andrés, «Education and the children's colonies in the Spanish Civil War (1936-1939): the images of the community ideal», Paedagogica Historica 51, no. 4 (2015): 455-477.

${ }^{28}$ Giovanni Di Franco, «Multiple correspondance analysis: one only or several techniques?», Quality \& Quantity. International Journal of Methodology 50, no. 3 (2016): 1299-1315.
} 
midades desnudas; (c) todos los niños/as están completamente vestidos, incluyendo algún tipo de calzado.

3) Felicidad, con las categorías: (a) al menos un niño/a está riendo sus dientes son visibles-; (b) al menos un niño/a está sonriendo —sus dientes no son visibles-; (c) todos los niños/as presentan expresiones serias.

4) Docente, con las categorías: (a) posición dominante -activo, al mando—; (b) posición marginal — pasivo, apenas visible—; (c) ausente.

5) Individualidad, con las categorías: (a) individual —los niños/as trabajan, juegan o actúan solos, pero también incluye los objetos materiales que son el resultado del trabajo individual—; (b) social —al menos dos niños interactúan entre sí, o niños interactúan con adultos, o niños y adultos aparecen cooperando en un proyecto colectivo, u objetos materiales como producto del trabajo en grupo-.

6) Actividad, con las categorías: (a) las denominadas tres R's en el mundo anglosajón -lectura, escritura y cálculo-; (b) trabajos manuales; (c) danza, música y teatro; (d) juego libre; (e) jardinería, cuidado de animales; (f) ciencias; (g) educación física, gimnasia, deportes y otras actividades relacionadas con el cuerpo.

7) Espacio, con las categorías: (a) dentro — del aula o de un edificio-; (b) fuera — de la escuela, al aire libre-.

8) Tiempo, con las categorías: (a) 1920-1924; (b) 1925-1929; (c) 19301934; (d) 1935-1939.

9) Lugar, ${ }^{29}$ con las categorías: (a) Gran Bretaña; (b) Estados Unidos; (c) Francia; (d) Alemania; (e) todos los demás países. Muchas de las imágenes en The New Era, exactamente 652 de las 944, se pueden ubicar en un país específico. Hemos podido rastrear 34 naciones diferentes, pero sólo de las mencionadas como categoría independiente se pudo encontrar un número de imágenes significativo y que permitiese la realización de comparaciones intranacionales.

\footnotetext{
${ }^{29}$ Sobre las diferencias entre lugar y espacio ver Marjolein Selten y Fleur van der Zandt, «Space vs. Place». http://geography.ruhosting.nl/geography/index.php?title=Space_vs._place (consultado el 3112-2017).
} 


\section{CARACTERÍSTICAS Y TEMÁTICA DE LAS IMÁGENES PUBLICADAS EN THE NEW ERA}

Una primera aproximación al estudio iconográfico de The New Era requiere realizar una descripción de los tipos de imágenes publicadas en la revista en el periodo estudiado. Los resultados quedan expuestos en la Tabla 1. Hemos agrupado el número total de las 944 imágenes en cuatro categorías. La más numerosa es la de fotografías: el 76,3\% de las imágenes publicadas se incluye en este grupo. También se puede encontrar una representación apreciable de dibujos: un 15,9\% de toda la producción iconográfica se encuadraría en este género. Las pinturas o cuadros sólo representan un 5,9\% del total, mientras que la presencia de gráficos, tablas y mapas, con un 1,9\% del total, es casi inapreciable.

Tabla 1. Tipos de Imágenes publicadas en The New Era (1920-1939), diferenciadas por periodos temporales

\begin{tabular}{|l|r|r|r|r|r|}
\hline \multicolumn{1}{|c|}{ Tipo de Imagen } & $\mathbf{1 9 2 0 - 1 9 2 4}$ & $\mathbf{1 9 2 5}-\mathbf{1 9 2 9}$ & $\mathbf{1 9 3 0 - 1 9 3 4}$ & $\mathbf{1 9 3 5 - 1 9 3 9}$ & \multicolumn{1}{c|}{ Total } \\
\hline Dibujo & 8 & 26 & 70 & 46 & 150 \\
& $17,4 \%$ & $13,8 \%$ & $13,3 \%$ & $24,9 \%$ & $15,9 \%$ \\
\hline Pintura & 19 & 23 & 8 & 6 & 56 \\
& $41,3 \%$ & $12,2 \%$ & $1,5 \%$ & $3,2 \%$ & $5,9 \%$ \\
\hline Fotografía & 19 & 137 & 432 & 132 & 720 \\
& $41,3 \%$ & $72,9 \%$ & $82,3 \%$ & $71,4 \%$ & $76,3 \%$ \\
\hline Gráfico/Tabla/Mapa & 0 & 2 & 15 & 1 & 18 \\
& $0,0 \%$ & $1,1 \%$ & $2,9 \%$ & $0,5 \%$ & $1,9 \%$ \\
\hline Total & 46 & 188 & 525 & 185 & 944 \\
& $100,0 \%$ & $100,0 \%$ & $100,0 \%$ & $100,0 \%$ & $100,0 \%$ \\
\hline
\end{tabular}

Chi-cuadrado $=157,8 ; \mathrm{df}=9 ; \mathrm{p}<.001$

El análisis de la producción iconográfica por periodos temporales arroja los siguientes resultados. En la primera etapa, 1920-1924, se publicaron muy pocas imágenes. Alrededor del $40 \%$ de estas fueron reproducciones de cuadros, generalmente realizadas por alumnos; mientras que otro $40 \%$ eran fotografías de escuelas, clases y retratos de educadores muy conocidos. En las siguientes etapas el número de fotografías se incrementó notablemente, hasta llegar a constituir el 70 u 80\% del total 
de la producción iconográfica de la revista. El número de dibujos, también creados casi en su totalidad por alumnos, experimentó un aumento relativo en el periodo 1935-1939.

Una gran parte de las imágenes, el 95,9\%, fue impresa en blanco y negro. Las imágenes en color aparecieron fundamentalmente en la etapa $1920-1924(23,9 \%)$ y siguieron presentes entre 1925 y $1929(12,8 \%)$, pero en el siguiente decenio desaparecieron completamente de la revista, que demostró con esta ausencia la mella que en ella hizo la crisis económica de 1929.

Otro elemento de análisis es el del tamaño de las imágenes (Tabla 2). A lo largo de los años, el número de imágenes que ocupaban una página completa tendió a decrecer, mientras que se incrementaron las de pequeño tamaño, menos de la mitad de una página. Fue en la etapa 1930-1934 cuando se imprimió el mayor número de imágenes $(\mathrm{N}=525)$, y más de la mitad de ellas $(52,2 \%)$ eran grandes, es decir, ocupaban gran parte de una página o incluso la página completa. Por el contrario, en el quinquenio 1935-1939 el número de imágenes decreció $(\mathrm{N}=185)$, al igual que sus dimensiones; la mayoría de ellas eran de un tamaño medio $(59,5 \%)$ o pequeño $(12,4 \%)$.

Tabla 2. Tamaño de las imágenes en The New Era (1920-1939), diferenciadas por periodos temporales

\begin{tabular}{|l|r|r|r|r|r|}
\hline Tamaño de la imagen & $\mathbf{1 9 2 0 - 1 9 2 4}$ & $\mathbf{1 9 2 5}-\mathbf{1 9 2 9}$ & $\mathbf{1 9 3 0 - 1 9 3 4}$ & $\mathbf{1 9 3 5 - 1 9 3 9}$ & \multicolumn{1}{c|}{ Total } \\
\hline Pequeño & 0 & 21 & 29 & 23 & 73 \\
& $0,0 \%$ & $11,2 \%$ & $5,5 \%$ & $12,4 \%$ & $7,7 \%$ \\
\hline Mediano & 21 & 53 & 205 & 110 & 389 \\
& $45,7 \%$ & $28,2 \%$ & $39,0 \%$ & $59,5 \%$ & $41,2 \%$ \\
\hline Grande & 21 & 84 & 274 & 46 & 425 \\
& $45,7 \%$ & $44,7 \%$ & $52,2 \%$ & $24,9 \%$ & $45,0 \%$ \\
\hline Página completa & 4 & 30 & 17 & 6 & 57 \\
& $8,7 \%$ & $16,0 \%$ & $3,2 \%$ & $3,2 \%$ & $6,0 \%$ \\
\hline Total & 46 & 188 & 525 & 185 & 944 \\
& $100,0 \%$ & $100,0 \%$ & $100,0 \%$ & $100,0 \%$ & $100,0 \%$ \\
\hline
\end{tabular}

Chi-cuadrado $=101,6 ; \mathrm{df}=9 ; \mathrm{p}<.001$ 
En un acercamiento inicial a los datos cuantitativos, observamos que aparecen tres contenidos iconográficos en The New Era claramente objetivables: imágenes de edificios escolares, paisajes y retratos de los representantes más conocidos del movimiento de la Nueva Educación (Tabla 3). En general, ninguno de estos tres temas tuvo mucha importancia, salvo una excepción significativa y muy presente en la primera década de la revista, la de los retratos de los héroes de la Nueva Educación.

Tabla 3. Temáticas de las imágenes en The New Era (1920-1939), diferenciadas por periodos temporales

\begin{tabular}{|l|r|r|r|r|r|}
\hline \multicolumn{1}{|c|}{ Temáticas } & $\mathbf{1 9 2 0 - 1 9 2 4}$ & $\mathbf{1 9 2 5}-\mathbf{1 9 2 9}$ & $\mathbf{1 9 3 0 - 1 9 3 4}$ & $\mathbf{1 9 3 5}-\mathbf{1 9 3 9}$ & Total \\
\hline Edificios & 4 & 19 & 23 & 5 & 51 \\
& $8,7 \%$ & $10,1 \%$ & $4,4 \%$ & $2,7 \%$ & $5,4 \%$ \\
\hline Paisajes & 1 & 6 & 6 & 0 & 13 \\
& $2,2 \%$ & $3,2 \%$ & $1,1 \%$ & $0,0 \%$ & $1,4 \%$ \\
\hline Retratos de adultos & 2 & 32 & 44 & 3 & 81 \\
& $4,3 \%$ & $17,0 \%$ & $8,4 \%$ & $1,6 \%$ & $8,6 \%$ \\
\hline Niños activos & 10 & 64 & 288 & 95 & 457 \\
& $21,7 \%$ & $34,0 \%$ & $54,9 \%$ & $51,4 \%$ & $48,4 \%$ \\
\hline Producciones de la infancia & 29 & 67 & 164 & 82 & 342 \\
& $63,0 \%$ & $35,6 \%$ & $31,2 \%$ & $44,3 \%$ & $36,2 \%$ \\
\hline Total & 46 & 188 & 525 & 185 & 944 \\
& $100,0 \%$ & $100,0 \%$ & $100,0 \%$ & $100,0 \%$ & $100,0 \%$ \\
\hline
\end{tabular}

Chi-cuadrado $=82,3 ; \mathrm{df}=12 ; \mathrm{p}<.001$

Edward Bernays estableció que uno de los poderosos mecanismos de propaganda era "the vivid dramatization of personality», y que las figuras públicas debían estudiar muy bien qué imagen querían transmitir de sí mismoas en relación con sus objetivos. ${ }^{30}$ De ahí el interés de analizar qué representantes de la Escuela Nueva fueron los elegidos para aparecer en las páginas de The New Era.

\footnotetext{
${ }^{30}$ Bernays, Propaganda, 156-157.
} 
El primer retrato que publicó la revista, en 1923, reunió todas las características objetivas de las imágenes que se deseaban destacar, pues se imprimió en tamaño grande y en papel satinado. La figura representada era Harold Baillie-Weaver, el Presidente de la NEF y Secretario General de la rama inglesa de la Sociedad Teosófica entre 1916 y 1921. La segunda personalidad cuyo retrato apareció en The New Era, en 1924, fue el famoso psicólogo Carl Gustav Jung. Y el tercer personaje que ocupó sus páginas, en 1925, fue George S. Arundale, quien, junto con Beatrice Ensor, había contribuido a fundar la Theosophical Fraternity in Education en 1915. La propia Ensor, creadora y editora de The New Era, publicó su retrato en la revista por primera vez en 1925, en gran tamaño. A lo largo de estos veinte años, incluyó cuatro fotografías suyas. En ellas aparece en el centro de la imagen, rodeada por otros iconos del movimiento de la Nueva Educación, casi siempre varones.

Ahora bien, el personaje que, sin duda, apareció retratado en más ocasiones en The New Era — cinco veces para ser precisos- fue el Premio Nóbel de Literatura Rabindranath Tagore, nombrado primer rector de la Universidad Nacional de la India, una institución promovida por un grupo de teósofos, incluido George S. Arundale. La escuela fundada por Tagore, Santiniketan, fue también la primera escuela nueva cuya fotografía recogió la revista, en 1924; una imagen que, además, se reprodujo en más ocasiones a lo largo de los años (Imagen 1). Por lo tanto, podemos afirmar que Rabindranath Tagore fue la personalidad escogida por The New Era como icono y símbolo de la Nueva Educación. La construcción que esta publicación hizo del literato y educador hindú como la figura icónica de su movimiento puede explicarse por varias razones. La primera, desde luego, es la estrecha relación que la familia Tagore mantuvo con la Sociedad Teosófica. ${ }^{31}$ La segunda fue el descubrimiento súbito que los espiritualistas - y los teósofos y muchos pioneros de la NEF lo eran- hicieron de Oriente como un tesoro espiritual, y su necesidad de convertir a la India en el corazón místico del mundo. ${ }^{32}$ La tercera conecta con el propio Tagore y su cambio de identidad tras el viaje a Londres en 1912, cuando empezó a escribir directamente en inglés y a postularse

\footnotetext{
${ }^{31}$ Mriganka Mukhopadhyay, «The Occult and the Orient. The Theosophical Society and the Socio-Religious Space in Colonial India», Presidency Historical Review 1, no. 2 (2015): 9-37.

${ }^{32}$ Isaac Lubelsky, Celestial India: Madame Blavatsky and the Birth of Indian Nationalism (Oakville, CT: Equinox Publication, 2012).
} 
como el nexo de unión entre Oriente y Occidente, considerándose uno de esos «poets and prophets» llamados a construir una modernidad global basada en la comunicación y el diálogo entre ambos mundos, buscando las raíces espirituales comunes. ${ }^{33}$ Los grupos teosóficos le ayudaron en su mise-en-scène de ese rol de apóstol transnacional divulgando fotografías como la que aparece en la Imagen 1, que cultivaban la fantasía oriental, y que se insertaban en textos en los que Tagore exponía sus ideales pedagógicos, que eran muy similares a los de la NEF. Es curioso que la fotografía elegida se contraponga a todos los principios educativos de la Escuela Nueva, mostrando al maestro en el centro del proceso de enseñanza-aprendizaje y a los alumnos realizando disciplinadamente un ejercicio propio de la escuela tradicional. El culto al héroe fue el mensaje dominante en esta fotografía, en la que sólo los árboles que constituyen el telón de fondo nos sugieren la cercanía con la naturaleza tan predicada por Tagore.

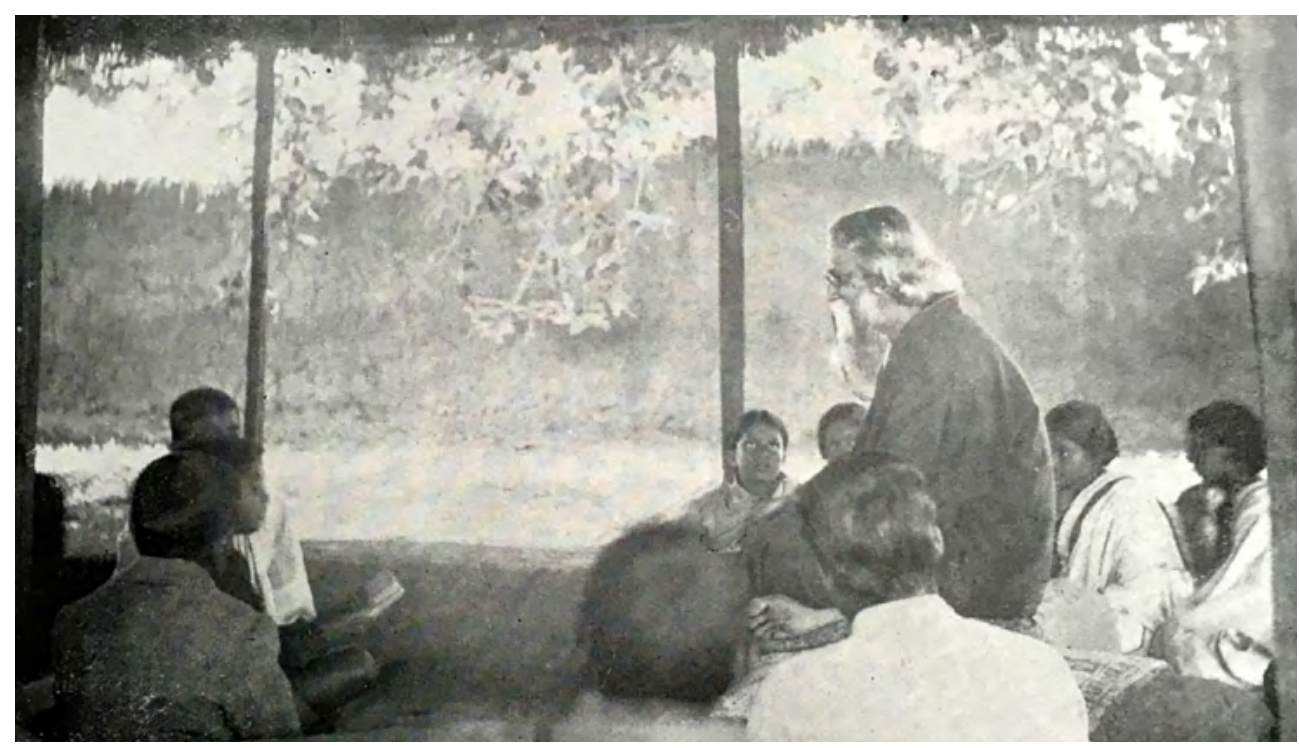

Imagen 1. Rabindranath Tagore en su escuela Santiniketan en Bolpur, India Fuente: «The Poet as Schoolmaster», The New Era 4 (1924): 84.

\footnotetext{
${ }^{33}$ Michael Collins, «History and the Postcolonial. Rabindranath Tagore's Reception in London, 19121913», The International Journal of the Humanities 4, no. 9 (2007): 71-83, y Daniel Laqua, «Transnational intellectual cooperation, the League of Nations, and the problem of order», Journal of Global History 6, no. 2 (2011): 231.
} 
A partir de Santiniketan The New Era mostró muchas imágenes de escuelas nuevas, que, generalmente, aparecían fotografiadas sólo en una ocasión. Sin embargo, algunos centros obtuvieron más publicidad que otros, cuantificando ésta por el número de veces que sus imágenes fueron expuestas en la revista (Tabla 4). Las escuelas con más fotografías publicadas fueron las del suburbio de Winnetka, USA $(\mathrm{N}=16)$; la Odenwaldschule de Alemania ( $\mathrm{N}=14)$; la Maison des Petits, Suiza $(\mathrm{N}=11)$ y la Francis Parker School de Chicago, USA (N=9). Lo más destacable de estos datos es la constatación de que la revista The New Era, publicada en Gran Bretaña y con editores ingleses, mostró más imágenes de escuelas extranjeras que nacionales. No por casualidad, Frensham Heights en Farnham, es el centro británico del que se divulgó el mayor número de fotografías $(\mathrm{N}=8)$. Su directora era Beatrice Ensor, que también era la editora de The New Era.

Tabla 4. Escuelas más fotografiadas en The New Era (1920-1939), organizadas por países/continentes

\begin{tabular}{|c|c|c|}
\hline Gran Bretaña & USA & Europa/Africa \\
\hline & Public Schools Winnetka: 16 & $\begin{array}{l}\text { Odenwaldschule } \\
\text { (Alemania): } 14 \\
\text { Maison des Petits (Suiza): } 11\end{array}$ \\
\hline \multirow{2}{*}{$\begin{array}{l}\text { Frensham Heights, } \\
\text { Farnham: } 8 \\
\text { Holt School, Liverpool: } 8\end{array}$} & $\begin{array}{l}\text { Francis Parker School, } \\
\text { Chicago: } 9\end{array}$ & \\
\hline & $\begin{array}{l}\text { Lincoln School, Nueva York: } \\
6 \\
\text { Grant School, Pasadena: } 6\end{array}$ & École Decroly (Bélgica): 6 \\
\hline $\begin{array}{l}\text { Bedales, Petersfield: } 5 \\
\text { St George School, } \\
\text { Harpenden: } 5 \\
\text { King Arthur Sch., } \\
\text { Musselburgh: } 5\end{array}$ & $\begin{array}{l}\text { Merril-Palmer School, } \\
\text { Detroit: } 5 \\
\text { Beaver County School, } \\
\text { Mass.: } 5\end{array}$ & $\begin{array}{l}\text { St. Peter School, Jo'burg } \\
\text { (Sudáfrica): } 5\end{array}$ \\
\hline $\begin{array}{l}\text { Northumberland Heath } \\
\text { School: } 4\end{array}$ & & $\begin{array}{l}\text { Hamburg } \\
\text { Gemeinschaftschule } \\
\text { (Alemania): } 4 \\
\text { Lauterwater (Sudáfrica): } 4\end{array}$ \\
\hline $\begin{array}{l}\text { Bierton Road Sch., } \\
\text { Birmingham: } 3\end{array}$ & & École des Roches (Francia): 3 \\
\hline
\end{tabular}


Claramente, el tema central de las imágenes publicadas era la infancia (Tabla 3); el mensaje que la revista deseó transmitir con más insistencia fue el enfoque paidocéntrico de la Nueva Educación. En el 48,4\% de estas representaciones aparecen niños implicados activamente en tareas educativas o de la vida cotidiana, bien acompañados de docentes y adultos o bien solos o en grupos infantiles. El 36,2\% de las imágenes también se relaciona de alguna manera con la infancia, pues agrupa los cuadros, dibujos y otros productos artísticos realizados por los propios niños. El arte infantil fue uno de los temas iconográficos más visible en The New Era, especialmente en sus cinco primeros años de vida, en los que se esmeraron en publicar fotografías a todo color de cuadros realizados por niños muy talentosos.

Si bien con las imágenes de escuelas, la revista se esforzó en mostrar el internacionalismo del movimiento, con las fotografías de niños manifestó su clara orientación anglosajona (Tabla 5), pues gran parte de las representaciones infantiles o con grupos de niños y adultos/docentes $(\mathrm{N}=457)$ proceden de Gran Bretaña $(\mathrm{N}=147)$ o de USA $(\mathrm{N}=88)$. Los otros dos países con una muestra significativa de imágenes son Francia $(\mathrm{N}=27)$ y Alemania $(\mathrm{N}=21)$, ambos en el continente europeo. Pocas fotografías proceden de otros mundos ajenos a la cultura occidental, siendo destacable sólo la presencia de India $(\mathrm{N}=15)$ y URSS $(\mathrm{N}=11)$.

Tabla 5. Niños y niñas representados en The New Era (1920-1939), según países

\begin{tabular}{|l|r|r|r|r|r|r|}
\hline \multicolumn{1}{|c|}{ Sexo } & $\begin{array}{c}\text { Gran } \\
\text { Bretaña }\end{array}$ & \multicolumn{1}{c|}{ USA } & Francia & Alemania & $\begin{array}{c}\text { Resto del } \\
\text { mundo }\end{array}$ & Total \\
\hline Niños y niñas & 87 & 59 & 18 & 9 & 78 & 251 \\
& $59,2 \%$ & $67,0 \%$ & $66,7 \%$ & $42,9 \%$ & $44,8 \%$ & $54,9 \%$ \\
\hline Niño o niña & 4 & 4 & 0 & 4 & 22 & 34 \\
& $2,7 \%$ & $4,5 \%$ & $0,0 \%$ & $19,0 \%$ & $12,6 \%$ & $7,4 \%$ \\
\hline Niños o niñas & 56 & 25 & 9 & 8 & 74 & 172 \\
& $38,1 \%$ & $28,4 \%$ & $33,3 \%$ & $38,1 \%$ & $42,5 \%$ & $37,6 \%$ \\
\hline Total & 147 & 88 & 27 & 21 & 174 & 457 \\
& $100,0 \%$ & $100,0 \%$ & $100,0 \%$ & $100,0 \%$ & $100,0 \%$ & $100,0 \%$ \\
\hline
\end{tabular}

Chi-cuadrado $=28,1 ; \mathrm{df}=8 ; \mathrm{p}<.001$ 


\section{REPRESENTACIONES ICONOGRÁFICAS DE LA NUEVA EDUCACIÓN EN THE NEW ERA}

Las tres revistas que se constituyeron en órganos de expresión del movimiento de la Escuela Nueva adoptaron como tarea fundamental la propagación de sus ideales. En The New Era textos e imágenes se aliaron para mostrar e ilustrar los grandes principios innovadores. Partimos de la premisa de que aquellas representaciones con una elevada presencia iconográfica se identificaron con las que los responsables de la revista querían fijar de una manera más permanente y eficaz en las mentes de sus audiencias, es decir, fueron a las que se concedió mayor fuerza propagandística. A partir de este presupuesto, hemos organizado el análisis de nuestra serie fotográfica de acuerdo con seis ideas que universalmente se aceptan como características de la Escuela Nueva: coeducación, actividad, libertad, contacto con la naturaleza, paidocentrismo, e individualización vs socialización.

\section{Coeducación}

El movimiento de la Escuela Nueva propagó la idea de que los dos sexos debían educarse conjuntamente y realizar actividades comunes. Si analizamos las 457 imágenes con presencia de niños y niñas que se publicaron en The New Era entre 1920 y 1939 (Tabla 5) comprobamos que se apostó por la vía de la coeducación, pues en el 54,9\% de las fotografías niños y niñas aparecen juntos. Sin embargo, podemos percibir diferencias significativas por países: las imágenes de USA (67\%) y Francia $(66,7 \%)$ muestran muchos más grupos de ambos sexos que las de Gran Bretaña $(59,2 \%)$, Alemania $(42,9 \%)$ o el resto del mundo $(44,8 \%)$.

Sin embargo, es interesante destacar que la coeducación no es la opción exclusiva de The New Era; un 37,6\% de las imágenes muestran a niños y niñas por separado, y en ellas, generalmente, los varones aparecen implicados en actividades educativas consideradas tradicionalmente como masculinas, por ejemplo, los trabajos manuales; mientras que a las chicas se las presenta participando en actividades de carácter expresivo, como la danza.

Son realmente muy poco significativas las escasas fotografías en las que aparece un niño o una niña en solitario, generalmente con gesto de 
concentración (7,4\%). Catherine Burke y Ian Grosvenor apuntaron que esta representación era característica de la "progressive image» en historia de la educación, porque servía para relajar la tensión entre individualismo y colectivismo, pues este último podía ser asociado por el público con la «Utopian iconography of socialist states», y crear cierta ansiedad y hasta rechazo hacia las escuelas nuevas. ${ }^{34}$ Quizás este indicador es propio de las fotografías posteriores a la II Guerra Mundial que ellos analizaron en su artículo, pero no es significativo en las imágenes previas a 1939 publicadas en The New Era.

Tabla 6. Niños y niñas representados en The New Era (1920-1939), diferenciados por periodos temporales

\begin{tabular}{|l|r|r|r|r|r|}
\hline \multicolumn{1}{|c|}{ Sexo } & $\mathbf{1 9 2 0 - 1 9 2 4}$ & $\mathbf{1 9 2 5 - 1 9 2 9}$ & $\mathbf{1 9 3 0 - 1 9 3 4}$ & $\mathbf{1 9 3 5 - 1 9 3 9}$ & \multicolumn{1}{c|}{ Total } \\
\hline Niños y niñas & 2 & 42 & 167 & 40 & 251 \\
& $20,0 \%$ & $65,6 \%$ & $58,0 \%$ & $42,1 \%$ & $54,9 \%$ \\
\hline Niño o niña & 0 & 2 & 23 & 9 & 34 \\
& $0,0 \%$ & $3,1 \%$ & $8,0 \%$ & $9,5 \%$ & $7,4 \%$ \\
\hline Niños o niñas & 8 & 20 & 98 & 46 & 172 \\
& $80,0 \%$ & $31,3 \%$ & $34,0 \%$ & $48,4 \%$ & $37,6 \%$ \\
\hline Total & 10 & 64 & 288 & 95 & 457 \\
& $100,0 \%$ & $100,0 \%$ & $100,0 \%$ & $100,0 \%$ & $100,0 \%$ \\
\hline
\end{tabular}

Chi-cuadrado $=19,3 ; \mathrm{df}=6 ; \mathrm{p}=.004$

Si comparamos la evolución de las representaciones iconográficas de la coeducación a lo largo de estas dos décadas (Tabla 6), descubrimos que fueron mucho más numerosas en la etapa 1925-1929 (65,6\%), disminuyendo significativamente en el quinquenio 1935-1939 (42,1\%), al mismo tiempo que aumentaban la imágenes de niños o niñas representados por separado, lo cual da a entender una menor implicación de The New Era con el ideal pedagógico de la coeducación desde mediados de los años treinta, quizás por la dificultad de encontrar escuelas que la aplicaran en toda su pureza y que pudieran facilitar material gráfico para la revista.

\footnotetext{
${ }^{34}$ Burke y Grosvenor, «The progressive image in the history of education», 160.
} 


\section{Actividad}

No cabe duda de que la idea de actividad es la espina dorsal del movimiento de la Escuela Nueva que, no en vano, se denominó en los países francófonos «école active». La forma que hemos elegido de objetivar este principio es categorizar las diferentes actividades de carácter educativo que quedaron reflejadas en las representaciones visuales publicadas en The New Era, diferenciándolas, con propósitos comparativos, por países (Tabla 7) y por periodos temporales (Tabla 8).

Tabla 7. Actividades presentes en las imágenes de The New Era (1920-1939), según países

\begin{tabular}{|l|r|r|r|r|r|r|}
\hline \multicolumn{1}{|c|}{ Actividad } & $\begin{array}{r}\text { Gran } \\
\text { Bretaña }\end{array}$ & USA & Francia & Alemania & $\begin{array}{c}\text { Resto del } \\
\text { mundo }\end{array}$ & Total \\
\hline 3Rs & 23 & 6 & 3 & 2 & 27 & 61 \\
& $15,6 \%$ & $6,8 \%$ & $11,1 \%$ & $9,5 \%$ & $15,5 \%$ & $13,3 \%$ \\
\hline Trabajos Manuales & 32 & 42 & 10 & 5 & 59 & 148 \\
& $21,8 \%$ & $47,7 \%$ & $37,0 \%$ & $23,8 \%$ & $33,9 \%$ & $32,4 \%$ \\
\hline Danza/Teatro/ & 33 & 26 & 5 & 3 & 13 & 80 \\
Música & $22,4 \%$ & $29,5 \%$ & $18,5 \%$ & $14,3 \%$ & $7,5 \%$ & $17,5 \%$ \\
\hline Juego libre & 31 & 5 & 4 & 6 & 33 & 79 \\
& $21,1 \%$ & $5,7 \%$ & $14,8 \%$ & $28,6 \%$ & $19,0 \%$ & $17,3 \%$ \\
\hline Jardinería/Cuidado & 5 & 4 & 2 & 2 & 15 & 28 \\
de animales & $3,4 \%$ & $4,5 \%$ & $7,4 \%$ & $9,5 \%$ & $8,6 \%$ & $6,1 \%$ \\
\hline Ciencias & 12 & 4 & 1 & 2 & 10 & 29 \\
& $8,2 \%$ & $4,5 \%$ & $3,7 \%$ & $9,5 \%$ & $5,7 \%$ & $6,3 \%$ \\
\hline Educación Física/ & 11 & 1 & 2 & 1 & 17 & 32 \\
Deporte/Gimnasia & $7,5 \%$ & $1,1 \%$ & $7,4 \%$ & $4,8 \%$ & $9,8 \%$ & $7,0 \%$ \\
\hline Total & 147 & 88 & 27 & 21 & 174 & 457 \\
& $100,0 \%$ & $100,0 \%$ & $100,0 \%$ & $100,0 \%$ & $100,0 \%$ & $100,0 \%$ \\
\hline
\end{tabular}

Chi-cuadrado $=58,9 ; \mathrm{df}=24 ; \mathrm{p}<.001$

El primer mensaje propagandístico que transmiten las 457 imágenes que representan actividades educativas es que, efectivamente, en la Escuela Nueva se produjo una transformación del currículum escolar (Ta- 
bla 7). Las fotografías que muestran los contenidos tradicionales, los de carácter cognitivo, que están identificados como las 3Rs (lectura, escritura y cálculo) y con las enseñanzas científicas, constituyen solamente el $19,6 \%$ de esta serie iconográfica. Sin embargo, las imágenes que muestran actividades de carácter expresivo, relacionadas con el arte (danza, teatro o música, $17,5 \%)$, el juego libre $(17,3 \%)$ y, sobre todo, los trabajos manuales $(32,4 \%)$, se elevan al $67,2 \%$ del conjunto, y tienen la característica común de que todas ellas potencian la expresión del yo infantil y ayudan a su educación integral. Así, uno de cada tres niños aparece en las fotografías de The New Era construyendo o fabricando algún objeto. Un caso típico es el de la manufactura de instrumentos musicales que, en una segunda fase, serían utilizados para interpretar una obra u organizar un recital (Imagen 2 e Imagen 3).

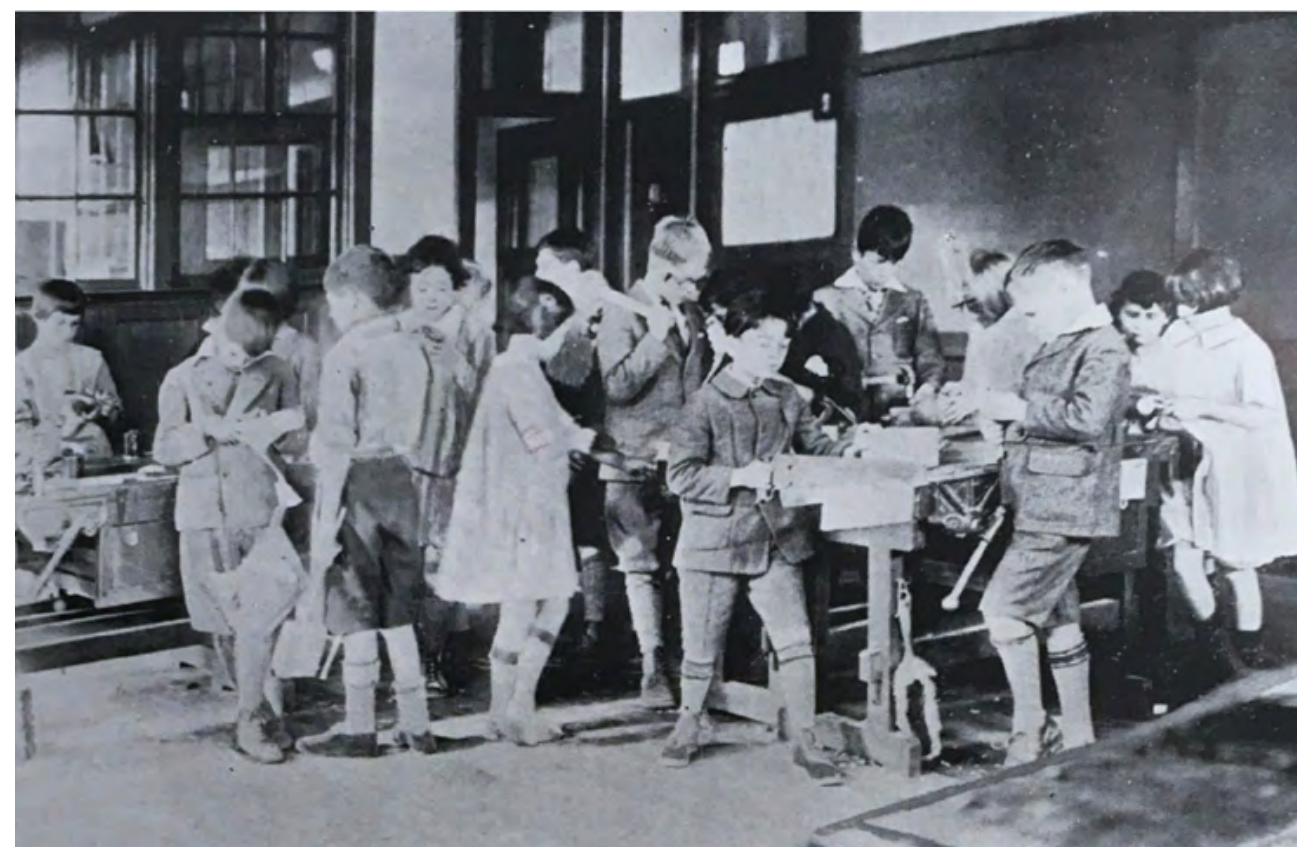

Imagen 2. Trabajos Manuales en la Lincoln School, Nueva York

Fuente: «Fourth Grade Instrument Makers in the Workshop», The New Era 8, no. 1 (1927): 10. 


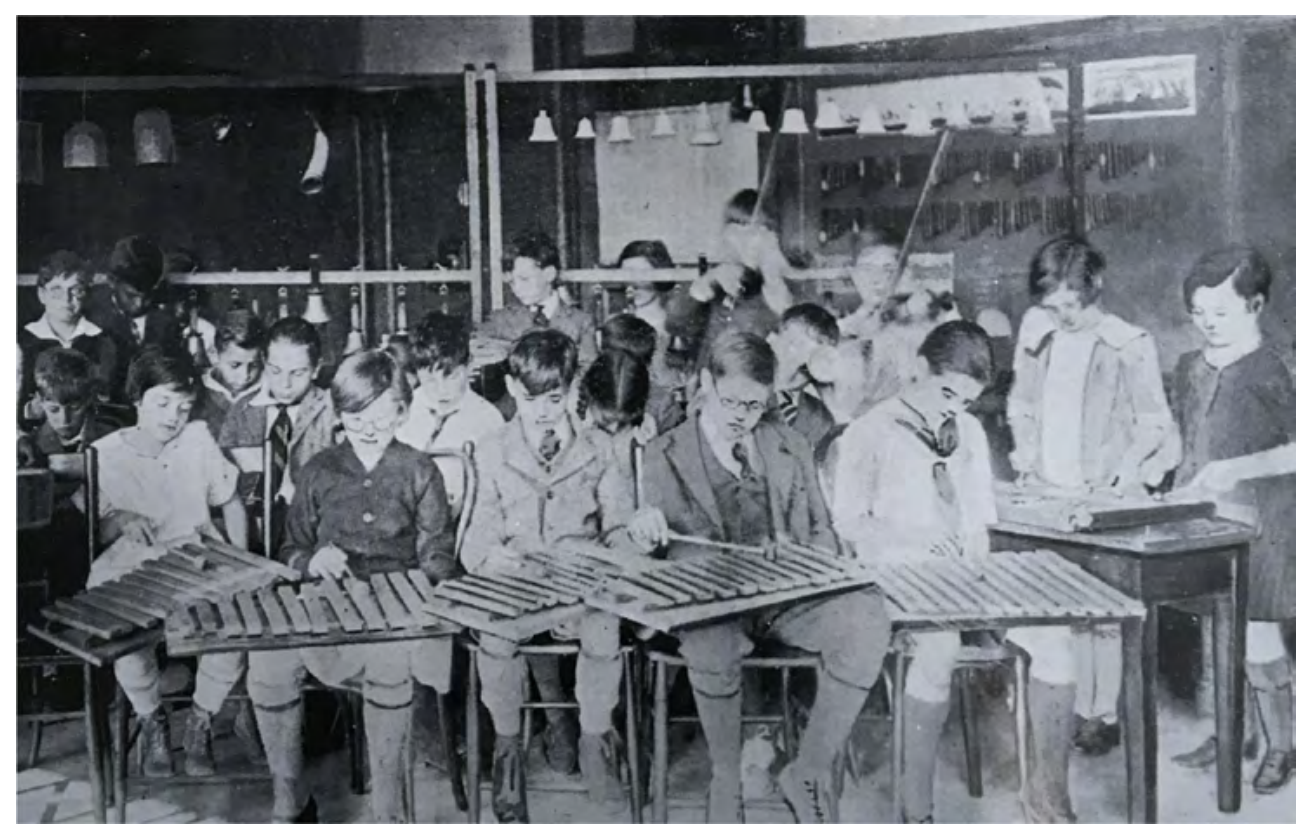

Imagen 3. Clase de Música en la Lincoln School, Nueva York Fuente: «The Marimba-makers try their instruments», The New Era 8, no. 1 (1927): 10.

Podemos advertir algunas variaciones en la representación de la idea de actividad según los países. Así, en las fotografías realizadas en Estados Unidos los trabajos manuales, arts \& crafts, son una ocupación más frecuentemente captada que en cualquier otro país (47,7\%); sin embargo, el trabajo libre parece más identificado con el continente europeo. Apenas se encuentran imágenes norteamericanas que impliquen el aprendizaje de las técnicas instrumentales de lectura, escritura y cálculo. Parece que la iconografía proveniente de USA quería representar el principio de John Dewey de «learning by doing», plasmándolo en la metodología del aprendizaje por proyectos cuya inspiración se le adjudicaba siempre, y muy erróneamente, al filósofo norteamericano.

También es posible encontrar diferencias en las representaciones de la idea de actividad a lo largo de las dos décadas (Tabla 8). Y la gran variación es el decreciente número de imágenes dedicadas a las ocupaciones expresivas y creativas, como la danza, el teatro y la música, en los años treinta, mientras que aumentaba el énfasis concedido a la gimnasia, el deporte y otras actividades físicas que implicaban el cuidado y el for- 
talecimiento del cuerpo. The New Era adaptó de este modo su mensaje para conectar con la amenaza que suponía el triunfo de los regímenes autoritarios en la Europa de los años treinta y el miedo que existía entre la población a otra gran guerra, para la que se necesitaría una juventud muy bien preparada físicamente.

Tabla 8. Actividades presentes en las imágenes de The New Era (1920-1939), diferenciadas por periodos temporales

\begin{tabular}{|l|r|r|r|r|r|}
\hline \multicolumn{1}{|c|}{ Actividad } & $\mathbf{1 9 2 0 - 1 9 2 4}$ & $\mathbf{1 9 2 5}-\mathbf{1 9 2 9}$ & $\mathbf{1 9 3 0 - 1 9 3 4}$ & $\mathbf{1 9 3 5 - 1 9 3 9}$ & \multicolumn{1}{c|}{ Total } \\
\hline 3Rs & 4 & 12 & 32 & 13 & 61 \\
& $40,0 \%$ & $18,8 \%$ & $11,1 \%$ & $13,7 \%$ & $13,3 \%$ \\
\hline Trabajos Manuales & 1 & 17 & 97 & 33 & 148 \\
& $10,0 \%$ & $26,6 \%$ & $33,7 \%$ & $34,7 \%$ & $32,4 \%$ \\
\hline Danza/Teatro/Música & 4 & 18 & 49 & 9 & 80 \\
& $40,0 \%$ & $28,1 \%$ & $17,0 \%$ & $9,5 \%$ & $17,5 \%$ \\
\hline Juego libre & 0 & 7 & 54 & 18 & 79 \\
& $0,0 \%$ & $10,9 \%$ & $18,8 \%$ & $18,9 \%$ & $17,3 \%$ \\
\hline Jardinería/Cuidado de & 1 & 4 & 14 & 9 & 28 \\
animales & $10,0 \%$ & $6,3 \%$ & $4,9 \%$ & $9,5 \%$ & $6,1 \%$ \\
\hline Ciencias & 0 & 5 & 22 & 2 & 29 \\
& $0,0 \%$ & $7,8 \%$ & $7,6 \%$ & $2,1 \%$ & $6,3 \%$ \\
\hline Educación Física/ & 0 & 1 & 20 & 11 & 32 \\
Deporte/Gimnasia & $0,0 \%$ & $1,6 \%$ & $6,9 \%$ & $11,6 \%$ & $7,0 \%$ \\
\hline Total & 10 & 64 & 288 & 95 & 457 \\
& $100,0 \%$ & $100,0 \%$ & $100,0 \%$ & $100,0 \%$ & $100,0 \%$ \\
\hline
\end{tabular}

Chi-cuadrado $=37,9 ; \mathrm{df}=18 ; \mathrm{p}=.004$

\section{Libertad}

La idea de libertad es una de las más características del movimiento de la Escuela Nueva, y una de las que más se divulgó como motto, lema o mantra de la Nueva Educación. También fue la más abierta a múltiples interpretaciones. Muy ligada, por una parte, a los conceptos de liberación y auto-expresión infantil y, por otra, a los de self-government de los escolares, tuvo al menos dos vertientes, una individual y otra social, que 
en muchas ocasiones entraron en conflicto. Por eso, no resulta nada fácil encontrar categorías objetivables y observables que permitan simbolizar iconográficamente la idea de libertad. Decidimos finalmente identificarla con la desnudez por varias razones. Una de ellas es que esta identificación es muy habitual en el arte contemporáneo, en el que la figura desnuda, además de representar la inocencia, puede significar también la liberación de la vestimenta. La ropa simboliza, en un sentido literal, todas aquellas ataduras que constriñen y separan de la naturaleza, y, en un sentido metafórico, el poder que oprime al ser humano, por lo que su eliminación expresa la libertad individual.

Reforzó este planteamiento una segunda razón, y es que parece que los editores de The New Era compartieron esta misma connotación de la desnudez. El concepto de libertad educativa que esta publicación adoptó en sus orígenes fue el de libertad individual, «implying release from previous restraints and freedom to develop naturally». ${ }^{35} \mathrm{En}$ la portada del primer número de la revista, publicado en enero de 1920, apareció una imagen que tenía una enorme carga simbólica y con la que suponemos que se querían representar todos los ideales de la Nueva Educación (Imagen 4). Era un dibujo de un niño con una venda en los ojos, con alas angelicales y delante de una bola del mundo. Estaba desnudo salvo un sucinto taparrabos. Esta imagen, a la que se le han buscado muchos significados, transmite la idea de paidocentrismo —el niño como ángel que sobrevuela el mundo-, y también la de libertad —el niño que ha sido liberado de los grilletes que le impuso la educación tradicional—- ${ }^{36}$ Su desnudez parcial, en nuestra opinión, simboliza más el concepto de liberación que unas cadenas inexistentes. Además, la revista, en años posteriores, eligió dibujos de niños estilizados y desnudos, a veces a lomos de animales poderosos (Imagen 5), para representar la fuerza creadora de la infancia y sus posibilidades de dominar el mundo. ${ }^{37}$ La alegoría de niños sin ropa como símbolo de su crecimiento en libertad, sin constricciones ni inhibiciones, es una presencia habitual en el imaginario de los educadores innovadores. Burke y Grosvenor apuntaron que uno de los rasgos repetidos en "the representation of the progressive school»

\footnotetext{
${ }^{35}$ Jenkins, «New Education and its emancipatory interest», 141.

${ }^{36}$ Jürgen Oelkers, Reformpädagogik: Eine kritische Dogmengeschichte (Weinheim: Juventa, 20054), 344.

${ }^{37}$ Koslowski, Die New Era, 291.
} 
eran las piernas desnudas de los escolares mientras que jugaban o trabajaban. ${ }^{38}$ Burke ha reiterado recientemente que «in English progressive state education, the feet, particularly bare feet, were fundamental to the anticipated exuberance of being alive in the modern school», y que los momentos históricos que marcan enfoques experimentales de enseñanza y aprendizaje pueden reconocerse porque «the school pupil, alone or collectively, is presented through images of exposed limbs and aesthetically pleasing physical poses». ${ }^{39}$

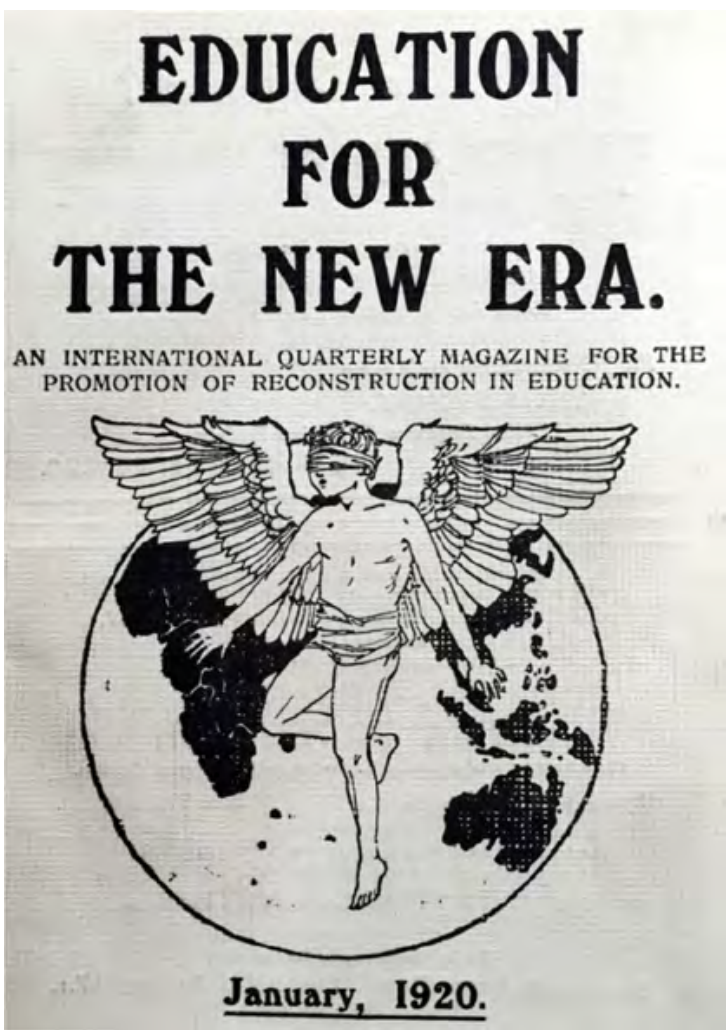

Imagen 4. Cubierta del primer número de The New Era Fuente: The New Era 1, no. 1 (1920): 1.

\footnotetext{
${ }^{38}$ Burke y Grosvenor, «The progressive image in the history of education», 161.

${ }^{39}$ Catherine Burke, «Feet, footwork, footwear, and "being alive" in the modern school», Paedagogica Historica 54, no. 1-2 (2018): 43. Ver también Xavier Riondet, «Élise Freinet: de l'expérience naturiste aux pratiques de l'École Freinet», Recherches \& éducations [En abierto], 8 Juin 2013, document 9 , mis en ligne le 15 juillet 2013, consultado el 11 enero 2018.
} 


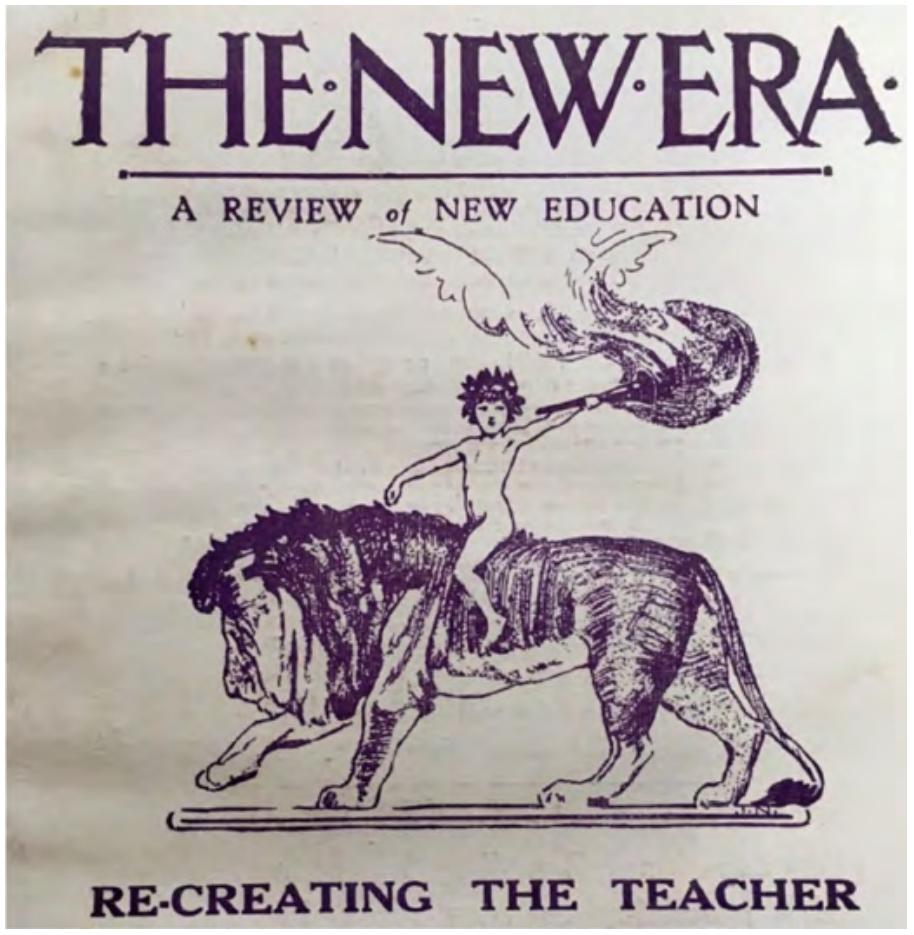

Imagen 5. Cubierta de The New Era en enero de 1926 Fuente: The New Era 7, no. 1 (1926): 1

A partir de estas premisas iconológicas, a priori no nos parecía muy aventurado suponer que una de las imágenes propagandísticas que cultivó The New Era fuese la de mostrar a la infancia realizando diferentes actividades artísticas y con diferentes grados de desnudez. En la Tabla 9 hemos recogido los resultados, que muestran que nuestra hipótesis de partida era totalmente equivocada. En la mayoría de las imágenes $(82,3 \%)$ los niños y niñas aparecen completamente vestidos; un porcentaje relativamente pequeño $(15,1 \%)$ muestra sus pies descalzos; y es casi imposible encontrar fotografías de desnudos integrales $(2,6 \%)$. No encontramos diferencias entre continentes y países, aunque sí podemos destacar que el número de imágenes en las que los niños aparecían con los pies descalzos decreció a lo largo de las dos décadas, mientras que se incrementaron las que mostraban cuerpos vestidos. Obviamente, la desnudez corporal suele ir unida con actividades físicas que tenían lugar fuera de la escuela; también puede coincidir con representaciones tea- 
trales o de danza. En algunas ocasiones, los niños descalzaban sus pies mientras que realizaban tareas instructivas dentro del aula (Imagen 6).

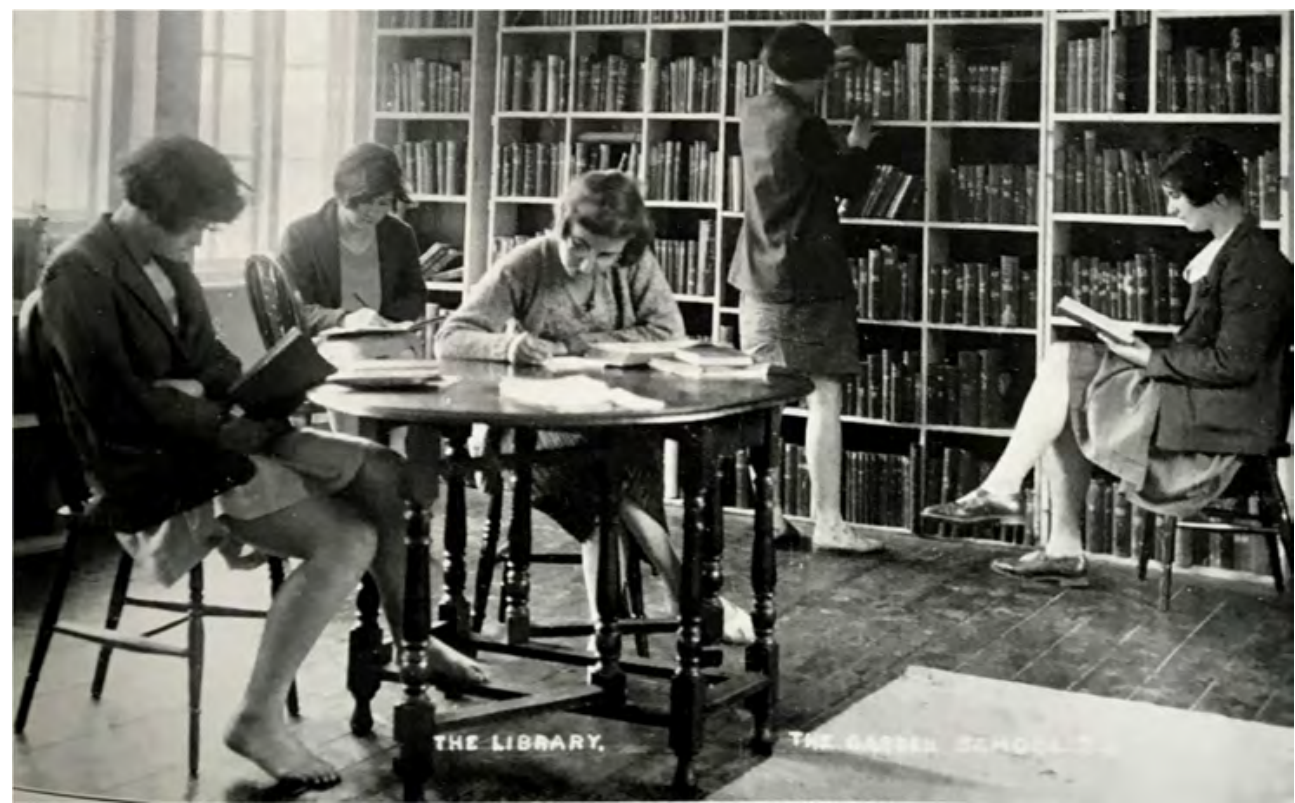

Imagen 6. Niñas con los pies descalzos en la biblioteca de la Garden School de Londres Fuente: The New Era 9, no. 10 (1926): 183.

Tabla 9. Desnudez en las imágenes de The New Era (1920-1939), diferenciada por períodos temporales

\begin{tabular}{|l|r|r|r|r|r|}
\hline \multicolumn{1}{|c|}{ Desnudez } & $\mathbf{1 9 2 0 - 1 9 2 4}$ & $\mathbf{1 9 2 5}-\mathbf{1 9 2 9}$ & $\mathbf{1 9 3 0 - 1 9 3 4}$ & $\mathbf{1 9 3 5 - 1 9 3 9}$ & \multicolumn{1}{c|}{ Total } \\
\hline Desnudo integral & 0 & 2 & 6 & 4 & 12 \\
& $0,0 \%$ & $3,1 \%$ & $2,1 \%$ & $4,2 \%$ & $2,6 \%$ \\
\hline $\begin{array}{l}\text { Pies/Piernas/Pecho } \\
\text { desnudos }\end{array}$ & 5 & 13 & 42 & 9 & 69 \\
\hline Vestidos & $50,0 \%$ & $20,3 \%$ & $14,6 \%$ & $9,5 \%$ & $15,1 \%$ \\
\hline Total & 5 & 49 & 240 & 82 & 376 \\
& $50,0 \%$ & $76,6 \%$ & $83,3 \%$ & $86,3 \%$ & $82,3 \%$ \\
\hline
\end{tabular}

Chi-cuadrado $=14,6 ; \mathrm{df}=6 ; \mathrm{p}=.024$ 
En cualquier caso, la desnudez integral es un fenómeno muy poco visible en The New Era. Es muy posible que sus editores la identificaran con la idea de libertad, pero también está claro que no pensaban que esta imagen pudiera utilizarse con propósitos propagandísticos, porque el público no iba a entender el simbolismo subyacente detrás de estas fotografías. Los padres y la sociedad en general, a pesar de su interés por la Nueva Educación, quizás pondrían por delante los prejuicios morales que despertaban los desnudos infantiles.

Pero entonces cabe preguntarse ¿qué imágenes utilizó The New Era para simbolizar la idea de libertad? Y la respuesta es que buscó representaciones muy tradicionales desde el punto de vista estético y artístico, como la reproducida en la Imagen 7 . No eran fotografías de carácter simbólico, sino dibujos en los que se insertaban los mensajes textuales, a manera de iconotextos. Esta forma de interdependencia de textos e imágenes, que se popularizó con los grabados ingleses de Hogarth y Rowlandson del siglo XVIII, ${ }^{40}$ implicaba un mensaje textual fácilmente comprensible con los códigos lingüísticos habituales, y, por lo tanto, mucho más accesible a todas las audiencias. Carecemos de estudios sobre el uso de iconotextos en historia de la educación, ${ }^{41}$ pero la Imagen 7 puede ser un ejemplo característico de sus posibilidades de análisis. Ante la dificultad de encontrar elementos simbólicos universalmente identificables con la idea de libertad, la revista divulgó un dibujo que imaginaba una manifestación infantil, en la que los casi bebés, con pancartas, expresaban sus reivindicaciones, todas ellas concentradas en la palabra libertad: a través del método, de la coeducación, de la psicología, del entorno, del arte o de la comprensión internacional. La palabra, de nuevo, dominaba la imagen.

\footnotetext{
${ }^{40}$ Peter Wagner, Reading Iconotexts. From Swift to the French Revolution (London: Reaktion Books, 1995).

${ }^{41}$ María del Mar del Pozo Andrés, «Imágenes e historia de la educación: construcción, reconstrucción y representación de las prácticas escolares en el aula», Historia de la Educación. Revista Interuniversitaria 25 (2006): 305-306.
} 


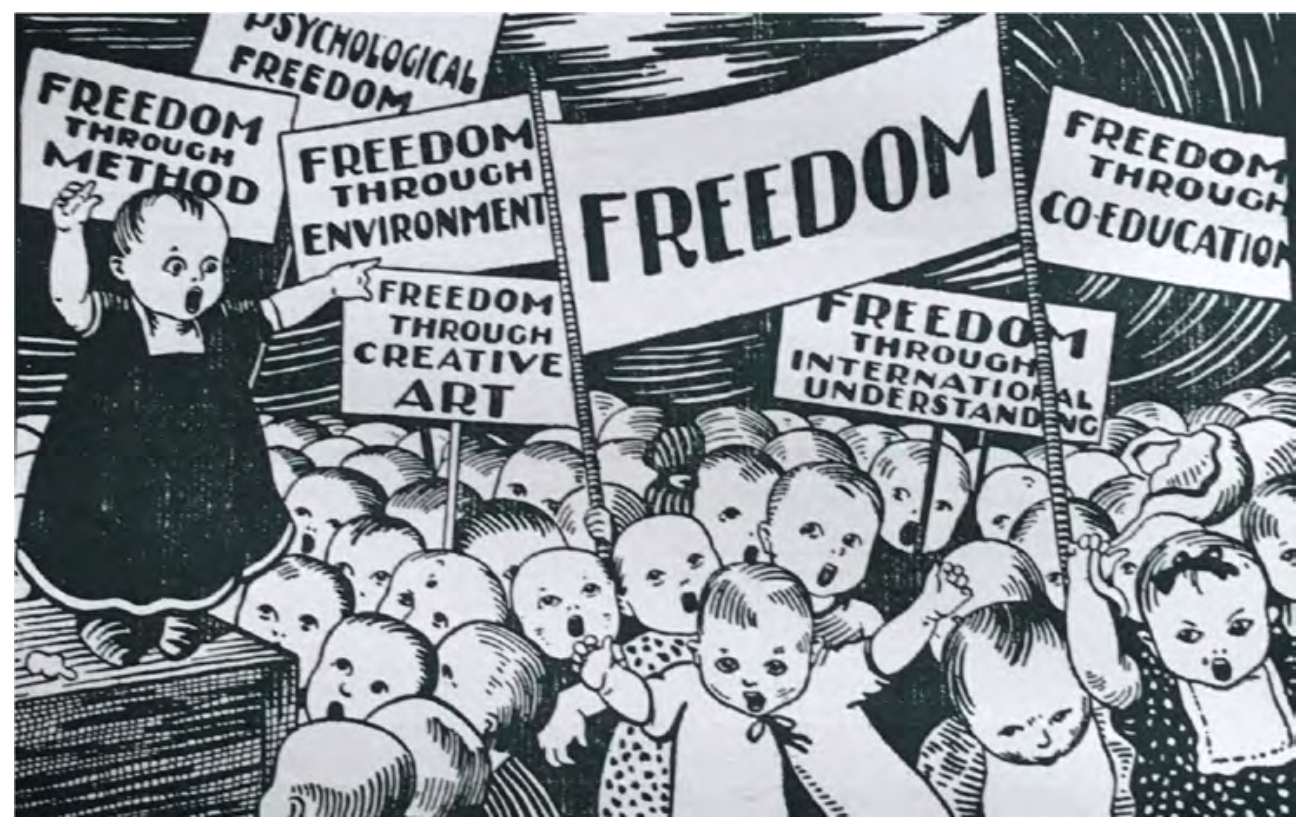

Imagen 7. Significado de la libertad en educación

Fuente: «The True Meaning of Freedom in Education», The New Era 8, no. 4 (1927): 1.

\section{Contacto con la naturaleza}

Uno de los treinta principios de la Nueva Educación publicados por Ferrière en 1925 establecía que toda escuela nueva debía estar situada en el campo, porque ese era el medio natural del niño y porque en él podría conseguir el máximo desarrollo de su cuerpo y de su espíritu. Pero, ¿cómo visibilizar y categorizar la idea de educación natural? Para ser consistentes con el resto de códigos utilizados en nuestro análisis serial, en este caso hemos clasificado todas las fotografías según las categorías «interior» $\mathrm{y}$ «exterior», que definen el espacio en el que se realizan las actividades educativas. La imagen habitual de la escuela tradicional era la de un espacio interior cerrado, un aula de clase donde los niños estaban constreñidos entre cuatro paredes y limitados por unos objetos que determinaban sus movimientos. La Escuela Nueva cultivó una imagen opuesta, la de los niños creciendo en un entorno natural y que permitía la espontaneidad y la libertad del cuerpo, un entorno en el que las actividades educativas se llevaban a cabo en el exterior, fuera del aula. 
Sin embargo, este planteamiento apriorístico no se corrobora con la evidencia iconográfica. La Tabla 10 nos muestra que The New Era publicó una proporción de imágenes tomadas en el interior de las escuelas, o de otros edificios, que está perfectamente equilibrada con las que se realizaron en los exteriores — calles, patios de recreo, jardines, la campiña o los bosques y las montañas-. Sí que se advierten diferencias en la representación de los espacios entre los diversos países; la mayoría de las fotografías provenientes de Estados Unidos reflejan interiores (69,3\%), mientras que una gran parte de las imágenes francesas se realizaron en exteriores $(63,0 \%)$, al igual que las alemanas $(57,1 \%)$. Esta diferencia entre la Europa continental y USA es una consecuencia del interés de The New Era por las que ya se habían convertido en las escuelas nuevas clásicas, esto es, los internados en el campo como Abbotsholme o Bedales o como la alemana Odenwaldschule (Imagen 8) y la francesa «l'École des Roches». En Estados Unidos este tipo de escuela era menos habitual; primaron las escuelas nuevas urbanas de las grandes ciudades, lo cual explica la dificultad de encontrar fotografías realizadas en entornos naturales. Por otra parte, la tradición de las escuelas al aire libre y de las Escuelas Bosque era europea, iniciada en la Alemania de principios del siglo xx, lo que justifica la mayor riqueza de fuentes iconográficas en Europa y la predilección por este tipo de representaciones de la educación natural.

Tabla 10. El uso del espacio en las imágenes de The New Era (1920-1939), según países

\begin{tabular}{|l|r|r|r|r|r|r|}
\hline \multicolumn{1}{|c|}{ Espacio } & \multicolumn{1}{c|}{$\begin{array}{c}\text { Gran } \\
\text { Bretaña }\end{array}$} & \multicolumn{1}{c|}{ USA } & Francia & Alemania & $\begin{array}{c}\text { Resto del } \\
\text { mundo }\end{array}$ & \multicolumn{1}{c|}{ Total } \\
\hline Interior & 69 & 61 & 10 & 9 & 85 & 234 \\
& $46,9 \%$ & $69,3 \%$ & $37,0 \%$ & $42,9 \%$ & $48,9 \%$ & $51,2 \%$ \\
\hline Exterior & 78 & 27 & 17 & 12 & 89 & 223 \\
& $53,1 \%$ & $30,7 \%$ & $63,0 \%$ & $57,1 \%$ & $51,1 \%$ & $48,8 \%$ \\
\hline Total & 147 & 88 & 27 & 21 & 174 & 457 \\
& $100,0 \%$ & $100,0 \%$ & $100,0 \%$ & $100,0 \%$ & $100,0 \%$ & $100,0 \%$ \\
\hline
\end{tabular}

Chi-cuadrado $=15,8 ; \mathrm{df}=4 ; \mathrm{p}=.003$

Lo que no podemos explicar es el equilibrio en el porcentaje de fotografías realizadas dentro y fuera de los muros escolares; tampoco es posible encontrar variaciones significativas a lo largo del tiempo. Pero el hecho de 
que constatemos una ligera supremacía de imágenes de interior no significa que en ellas no estuviera presente la innovación; en su mayoría representaban actividades fácilmente identificables con la Escuela Nueva. Por otra parte, aunque las imágenes de exterior no dominasen en The New Era, hay que comprender que habían crecido exponencialmente con respecto a épocas anteriores, en las que su presencia era muy escasa o inexistente.

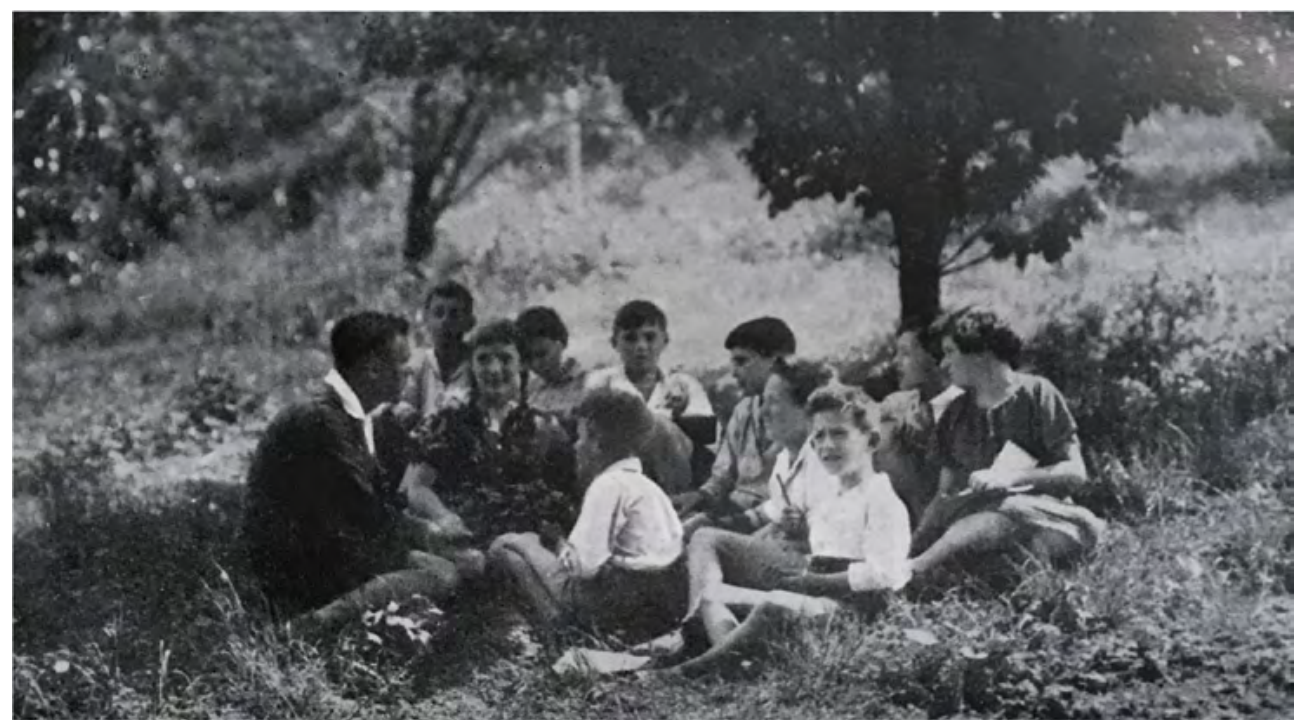

Imagen 8. Clase al Aire Libre en la Odenwaldschule Fuente: «An Open-Air Class. The Odenwaldschule The New Era 6, no. 10 (1925): 118.

\section{Paidocentrismo}

En las fotografías tradicionales de clase no es infrecuente encontrar al docente ocupando la posición central, o situado en esa parte de la imagen determinada por lo que se conoce como «proporción divina» $\mathrm{o}$ «regla de oro». ${ }^{42}$ En general, el maestro también suele aparecer en un plano físicamente superior al de los alumnos, por encima de ellos. Estas características específicas de la composición suelen combinarse con una figura de profesor que mira directamente a los ojos del observador

\footnotetext{
${ }^{42}$ Herbert E. Huntley, The divine proportion. A study in mathematical beauty (New York: Dover Publications, 1970), y Braster, «Educational change and Dutch classroom photographs», 29-30.
} 
y transmite una apariencia de control, la propia del magistrocentrismo que se identifica con la educación tradicional. La Escuela Nueva, por el contrario, se define por su paidocentrismo, es decir, por situar al niño en el centro del proceso de enseñanza-aprendizaje mientras que el docente se convierte en el guía, en el orientador de su proceso de crecimiento, lo que en el aprendizaje constructivista se ha definido como "from sage on the stage to guide on the side». ${ }^{43}$ Nuestro supuesto inicial es que este cambio se representó iconográficamente mediante un giro simbólico, en el que el profesor se movió desde el centro a los márgenes de la fotografía, miró a sus alumnos y no a los espectadores, se invisibilizó e incluso desapareció de la imagen.

Hemos constatado que este movimiento de los docentes desde la posición central hasta la tangencial de las fotografías es muy consistente y sostenido en diferentes espacios y tiempos, y se puede considerar como un indicador fiable de cómo viven su identidad profesional y de sus convicciones más profundas con respecto a las innovaciones pedagógicas. ${ }^{44}$ Por ello supusimos que sería uno de los rasgos más perceptibles en The New Era (Tabla 11).

Tabla 11. Posición del docente en las imágenes de The New Era (1920-1939), según países

\begin{tabular}{|l|r|r|r|r|r|r|}
\hline \multicolumn{1}{|c|}{ Docente } & $\begin{array}{c}\text { Gran } \\
\text { Bretaña }\end{array}$ & \multicolumn{1}{c|}{ USA } & Francia & Alemania & $\begin{array}{c}\text { Resto del } \\
\text { mundo }\end{array}$ & \multicolumn{1}{c|}{ Total } \\
\hline Dominante & 4 & 5 & 5 & 2 & 12 & 28 \\
& $2,7 \%$ & $5,7 \%$ & $18,5 \%$ & $9,5 \%$ & $6,9 \%$ & $6,1 \%$ \\
\hline Marginal & 29 & 8 & 3 & 2 & 27 & 69 \\
& $19,7 \%$ & $9,1 \%$ & $11,1 \%$ & $9,5 \%$ & $15,5 \%$ & $15,1 \%$ \\
\hline Ausente & 114 & 75 & 19 & 17 & 135 & 360 \\
& $77,6 \%$ & $85,2 \%$ & $70,4 \%$ & $81,0 \%$ & $77,6 \%$ & $78,8 \%$ \\
\hline Total & 147 & 88 & 27 & 21 & 174 & 457 \\
& $100,0 \%$ & $100,0 \%$ & $100,0 \%$ & $100,0 \%$ & $100,0 \%$ & $100,0 \%$ \\
\hline
\end{tabular}

Chi-cuadrado $=15,8 ; \mathrm{df}=8 ; \mathrm{p}=.045$

\footnotetext{
${ }^{43}$ Alison King, «From sage on the stage to guide on the side», College Teaching 41, no. 1 (1993): 30-35.

${ }^{44}$ María del Mar del Pozo Andrés, "La imagen de la mujer en la educación contemporánea», en Las mujeres en la construcción del mundo contemporáneo, eds. Teresa Marín Eced y María del Mar del Pozo Andrés (Cuenca: Diputación de Cuenca, 2002), 251-254.
} 
Y, de hecho, los resultados son absolutamente significativos: en el $78,8 \%$ de las imágenes de la revista en las que aparecen niños y niñas, los maestros están ausentes; en el 15,1\% de los casos en los que sí se muestran docentes, todos ellos están en una posición tangencial o marginal, como la mostrada en la Imagen 9, en la que el profesor observa el trabajo infantil, mezclado entre sus discípulos. Sólo en el 6,1\% de las imágenes la posición del maestro puede ser descrita como dominante.

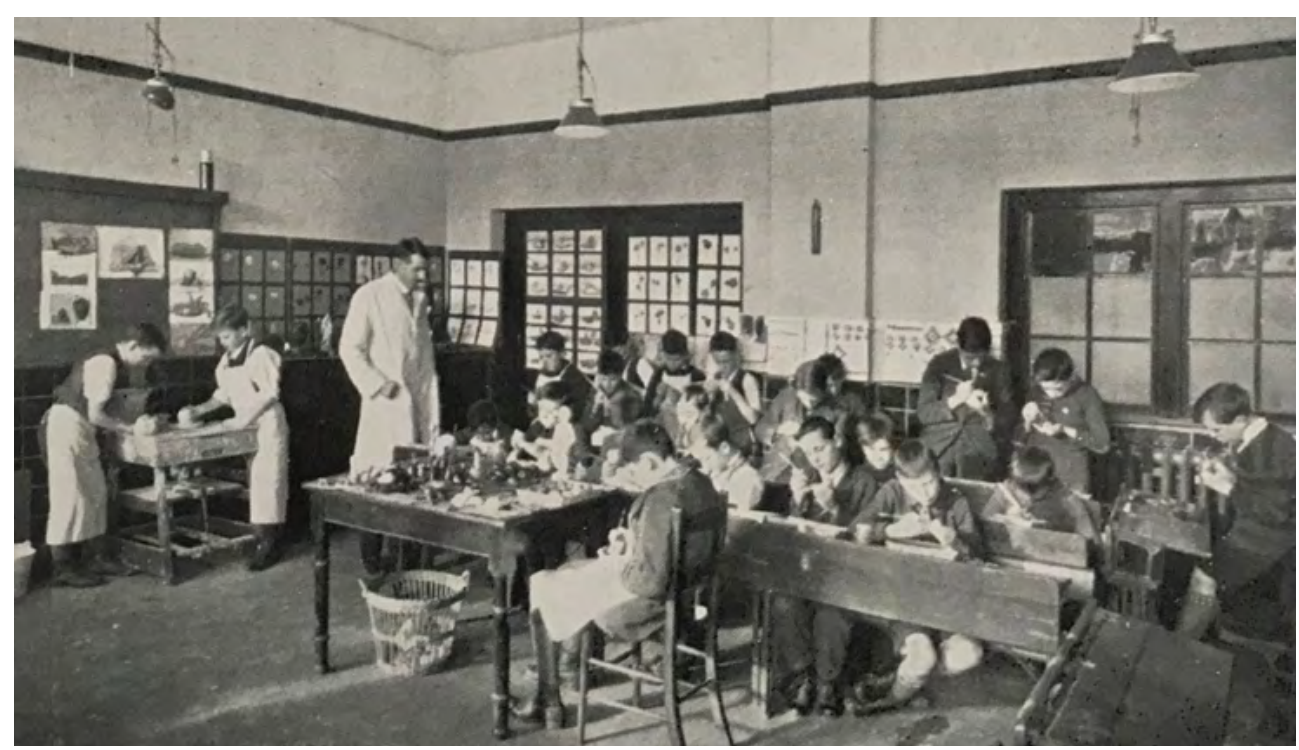

Imagen 9. Ejemplo de imagen de un maestro en posición tangencial Fuente: «Practical Work Room. Rangefield (L.C.C.) School, Dounham State, near Southend Village», The New Era 9, no. 34 (1928): s.p.

Un análisis comparativo de esta evolución a lo largo de las dos décadas estudiadas no aportó diferencias significativas; desde la primera etapa (1920-1925) hasta la última (1935-1939), el docente brilla por su ausencia. Sí que podemos percibir algunas variaciones intranacionales; mientras que en Gran Bretaña apenas encontramos representaciones de maestros en posición dominante, en Francia un 18,5\% siguen siendo retratados como figuras de control y autoridad. Es posible que esta diferencia sea un reflejo de la distinción entre el centralizado sistema educativo francés y el descentralizado sistema educativo británico. ${ }^{45}$ En cualquier

\footnotetext{
${ }^{45}$ Margaret S. Archer, Social origins of educational systems (London/New York: Routledge, 2013).
} 
caso, los editores de The New Era mostraron una marcada preferencia por publicar fotografías de Gran Bretaña y Estados Unidos en las que la ausencia del docente era bien visible.

\section{Individualización vs Socialización}

La dialéctica entre los principios de individualización y socialización hizo correr ríos de tinta entre los teóricos de la Escuela Nueva. El desarrollo individual, espiritual, expresivo y autónomo de la infancia, al mismo tiempo que su autopercepción como ser social y colaborativo, su integración en diferentes comunidades, y, en último término, su implicación en los destinos de la humanidad, eran los dos pilares en los que se sustentaba la paideia de la Nueva Educación. Aunque podían ser perfectamente compatibles, la narrativa de la innovación los convirtió casi en excluyentes, sobre todo porque se tendió a clasificar gran parte de los nuevos métodos como individualizados o socializados, a pesar de que esta categorización era artificial y poco realista.

Por eso, pensamos que el análisis iconográfico podría aportar un nuevo modo de enfocar las tensiones entre estos dos principios. Para poder abordar este estudio particular era necesario clasificar las imágenes publicadas en The New Era según dos categorías: individual y social. Una imagen fue categorizada como «individual» si un niño estaba trabajando, jugando o actuando en soledad; es decir, si no interactuaba con otro niño o con un docente. Una imagen fue categorizada como «social» si al menos dos niños estaban interactuando entre ellos o con el profesor, o si niños solos o con adultos estaban cooperando en un proyecto colectivo. Por lo tanto, las imágenes de alumnos sentados en una clase y ocupados en sus propias actividades, sin hablar ni mostrar gestos de acercamiento hacia sus compañeros, fueron codificadas como «individuales». Muchas de ellas se publicaron con la etiqueta de Plan Dalton, el considerado más individualizado de todos los métodos de la Escuela Nueva, que fue muy popular en Gran Bretaña en los años veinte. ${ }^{46}$ Su iconografía habitual puede verse en la Imagen 10, en la que aparecen todos los símbolos visuales propios de este método, entre ellos la biblioteca y los libros como elemento central

\footnotetext{
${ }^{46}$ Piet van der Ploeg, Dalton Plan: Origins and Theory of Dalton Education (Deventer: Saxion Dalton University Press, 2013) y Piet van der Ploeg, «The Dalton Plan: recycling in the guise of innovation», Paedagogica Historica 49, no. 3 (2013): 314-329.
} 
de la fotografía. ${ }^{47}$ Las imágenes de niños trabajando conjuntamente en un proyecto (por ejemplo, construir un pueblo o una catedral), o interpretando una obra de teatro, o cantando juntos, fueron codificadas como «sociales». Muchas de ellas se publicaron con el título de método de proyectos, que la revista identificó frecuentemente con el plan Winnetka, en las que se representaban actividades relacionadas con el desarrollo de la humanidad, ${ }^{48}$ como la reconstrucción de un barco vikingo o de un poblado holandés en América, y asociadas a la teoría de la recapitulación tan en boga en Estados Unidos por esos años y que se ha considerado el origen de las pedagogías centradas en el niño. ${ }^{49}$ Hay pocas fotografías que se identifiquen en su pie con un método concreto de la Escuela Nueva. Llama especialmente la atención las escasas imágenes existentes sobre métodos tan conocidos como Decroly o Montessori. Por eso, en este artículo no se ha incluido un código especial con la denominación de todos los métodos innovadores.

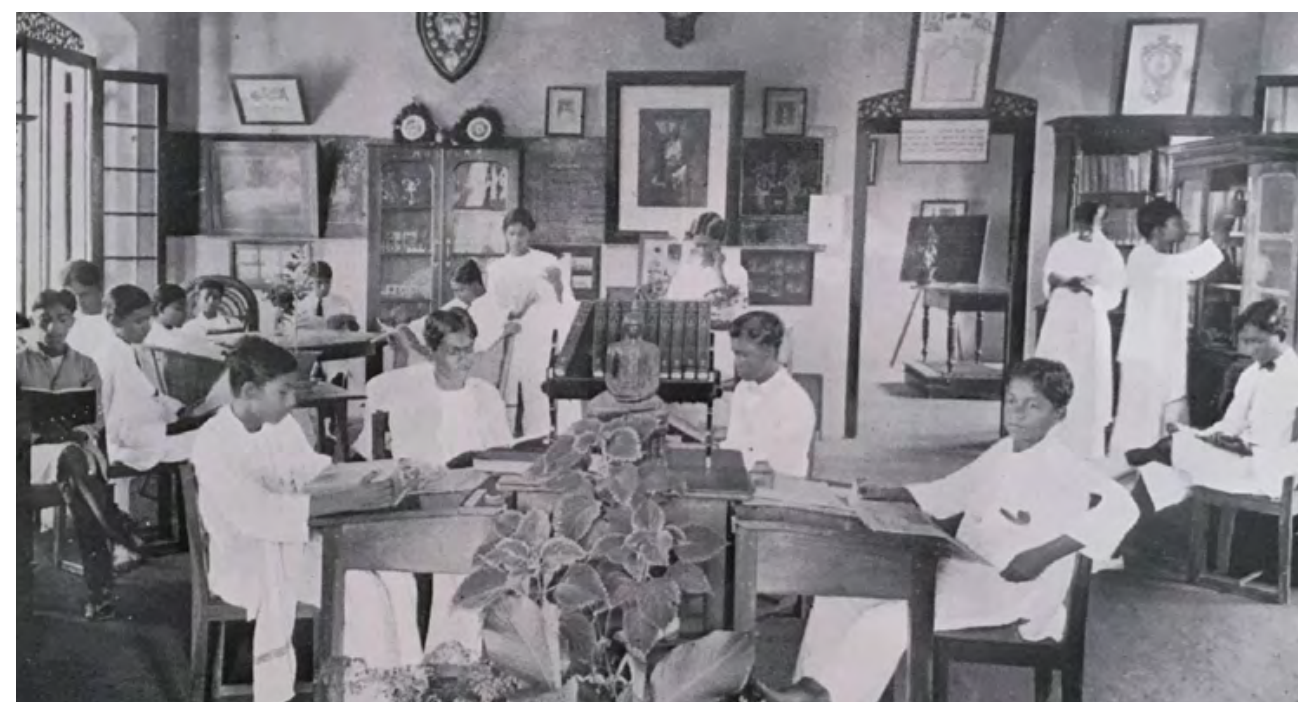

Imagen 10. Ejemplo de representación de la individualización

Fuente: «English Laboratory, Mahinda College, Ceylon», The New Era 5, no. 20 (1924): 126.

\footnotetext{
${ }^{47}$ María del Mar del Pozo Andrés y Sjaak Braster, «El Plan Dalton en España: Recepción y Apropiación (1920-1939)», Revista de Educación 377 (2017): 118.

${ }^{48}$ María del Mar del Pozo Andrés, «The transnational and national dimensions of pedagogical ideas: the case of the project method, 1918-1939», Paedagogica Historica 45, no 4-5 (2009): 561-584.

${ }^{49}$ Thomas Fallace, «The Savage Origins of Child-Centered Pedagogy, 1871-1913», American Educational Research Journal 52, no. 1 (2015): 73-103.
} 
¿Qué tendencia de la Nueva Educación, la individualizadora o la socializadora, prevaleció en The New Era? Los resultados de la Tabla 12 son muy claros: demuestran que las imágenes relacionadas con la socialización dominaron ampliamente a las caracterizadas como individualización $(75,1 \%$ frente a $24,9 \%)$. El estudio por áreas geográficas no es concluyente; no se encuentran diferencias significativas entre representaciones de Gran Bretaña, USA, Francia o Alemania. Aunque a priori pensábamos que las imágenes fabricadas en Gran Bretaña se identificarían mucho más con la idea de individualización, por el éxito del Plan Dalton en los años veinte, y que las provenientes de Estados Unidos tenderían a divulgar los ideales de la socialización, por la influencia de Dewey y su concepto de comunidad y por la asociación del Teachers College de la Universidad de Columbia con el método de proyectos, los datos no confirmaron esta hipótesis.

Tabla 12. Representación de la individualización y la socialización en las imágenes de The New Era (1920-1939), diferenciada por periodos temporales

\begin{tabular}{|l|r|r|r|r|r|}
\hline & $\mathbf{1 9 2 0 - 1 9 2 4}$ & $\mathbf{1 9 2 5}-\mathbf{1 9 2 9}$ & $\mathbf{1 9 3 0 - 1 9 3 4}$ & $\mathbf{1 9 3 5 - 1 9 3 9}$ & \multicolumn{1}{c|}{ Total } \\
\hline Individualización & 3 & 17 & 77 & 17 & 114 \\
& $30,0 \%$ & $26,6 \%$ & $26,7 \%$ & $17,9 \%$ & $24,9 \%$ \\
\hline Socialización & 7 & 47 & 211 & 78 & 343 \\
& $70,0 \%$ & $73,4 \%$ & $73,3 \%$ & $82,1 \%$ & $75,1 \%$ \\
\hline Total & 10 & 64 & 288 & 95 & 457 \\
& $100,0 \%$ & $100,0 \%$ & $100,0 \%$ & $100,0 \%$ & $100,0 \%$ \\
\hline
\end{tabular}

Chi-cuadrado $=3,2 ; \mathrm{df}=3 ; \mathrm{p}=.356$

La diferencia más significativa entre estas categorías aparece al introducir en nuestro análisis el factor temporal. En los primeros años veinte los aspectos caracterizados como individualización eran dominantes, no tanto por las actividades infantiles como por los productos y resultados, recogidos en la Tabla 13. Se percibe que la revista representó la individualidad principalmente a través de la publicación de las producciones artísticas infantiles, en definitiva, con el fruto de la expresión libre de niños y niñas, con «the creative self-expression of the child», que fue el tema del primer congreso organizado por Beatrice Ensor en Calais, en 
1921, tras el que se fundó la NEF. Los siguientes congresos también se centraron en el poder de la creatividad infantil. ${ }^{50}$ Sin embargo, en los años treinta la NEF revisó sus principios; el congreso de Niza de 1932 marcó un cambio de rumbo «from individual to social responsibility due to the prevailing political climate». ${ }^{51} \mathrm{Y}$ este cambio se reflejó en el imaginario de The New Era. En el quinquenio 1935-1939 se produjo un visible incremento de fotografías que simbolizaban la cooperación y la colaboración (Tabla 12), en las que se veía a muchos niños y niñas implicados conjuntamente en la realización de actividades expresivas.

Tabla 13. Representación de la individualización y la socialización en las imágenes de The New Era (1920-1939), diferenciada por periodos temporales (incluyendo las imágenes de cuadros, dibujos y otros objetos realizados por niños)

\begin{tabular}{|l|r|r|r|r|r|}
\hline & $\mathbf{1 9 2 0 - 1 9 2 4}$ & $\mathbf{1 9 2 5 - 1 9 2 9}$ & $\mathbf{1 9 3 0 - 1 9 3 4}$ & $\mathbf{1 9 3 5 - 1 9 3 9}$ & \multicolumn{1}{c|}{ Total } \\
\hline Individualización & 27 & 59 & 121 & 50 & 257 \\
& $71,1 \%$ & $51,3 \%$ & $33,8 \%$ & $37,3 \%$ & $39,8 \%$ \\
\hline Socialización & 11 & 56 & 237 & 84 & 388 \\
& $28,9 \%$ & $48,7 \%$ & $66,2 \%$ & $62,7 \%$ & $60,2 \%$ \\
\hline Total & 38 & 115 & 358 & 134 & 645 \\
& $100,0 \%$ & $100,0 \%$ & $100,0 \%$ & $100,0 \%$ & $100,0 \%$ \\
\hline
\end{tabular}

Chi-cuadrado $=27,6 ; \mathrm{df}=3 ; \mathrm{p}<.001$

El clima político de los años treinta trajo consigo una mayor preocupación de la NEF por la comprensión internacional, por el diálogo entre naciones y culturas, por el pacifismo y la introducción de la Liga de Naciones en las escuelas. Sin embargo, de estos temas apenas se encuentran evidencias iconográficas en The New Era. Una de las escasas fotografías publicadas es la Imagen 11, que muestra una actividad de cooperación internacional en la que niñas de varios países simbolizan, con sus manos unidas y su juego del corro - considerado desde la antropología social como un espacio de socialización femenina ${ }^{52}$ - la idea de colaboración entre países.

\footnotetext{
${ }^{50}$ Eckhardt Fuchs, «Educational sciences, morality and politics. International educational congresses in the early twentieth century», Paedagogica Historica 40, no. 5-6 (2004): 757-784.

${ }^{51}$ Jenkins, «The professional middle class and the social origins of progressivism», 59.

${ }^{52}$ Braster y del Pozo Andrés, «Education and the children's colonies in the Spanish Civil War (19361939)», 471.
} 


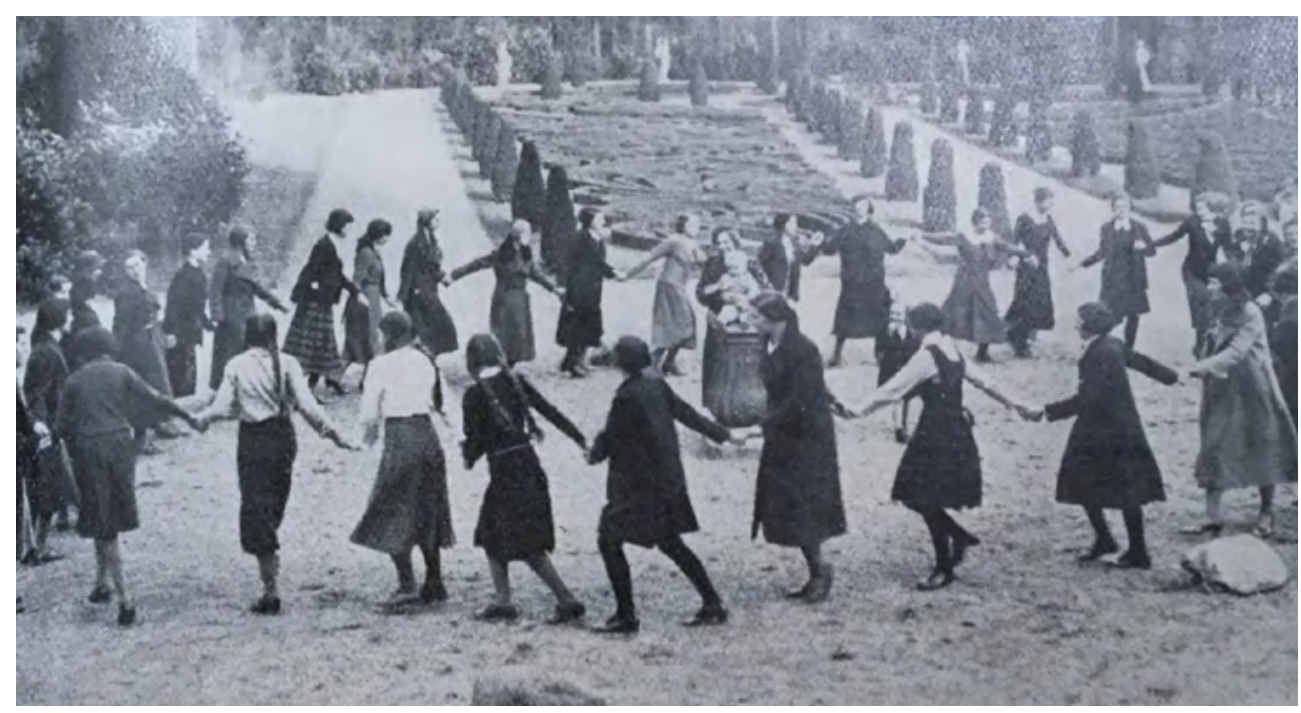

Imagen 11. Ejemplo de representación de la socialización

Fuente: «Dutch, English and Scots girls dancing in the grounds», The New Era 16, no. 5 (1935): 119.

Cabe preguntarse si la escasez de imágenes ligadas a la cooperación internacional se debió a que la revista, a pesar del cambio de orientación de la NEF, no les concedió valor propagandístico, o no creía que su divulgación tuviera los efectos deseados, o si, simplemente, no llegaban a su redacción fotografías de esta temática. Creemos que esta última explicación es la más verosímil. En un mundo que se preparaba para la guerra, las iniciativas internacionalistas no deseaban hacerse muy visibles. De hecho, The New Era publicó todos los artículos que encontró sobre experiencias de escuelas internacionales, y así, una revista que jamás había prestado atención a la educación española, difundió en dos años dos artículos sobre la Escuela Internacional creada por José Castillejo en Madrid. En ellos se apuntaba la realización de un ensayo metodológico basado en la adaptación del Plan Dalton. Y la fotografía publicada recogía algunos de los elementos simbólicos característicos de este método, representando, por lo tanto, la idea de individualidad (Imagen 12). En los textos, por el contrario, se acentuaba el ideal de la comprensión internacional. Así, se detallaba cómo se inculcaban en la escuela los valores pacifistas a partir de la enseñanza de la historia, sustituyéndose los ineficaces libros de texto por charlas con profesores de diferentes países que explicaban a los niños los hechos históricos desde sus propias, divergentes e 
incluso contradictorias perspectivas, dejándoles luego en libertad para que extrajeran sus conclusiones personales. «Peace cannot be attained by ignoring hatred, but rather by knowing it and suffering it». ${ }^{53}$

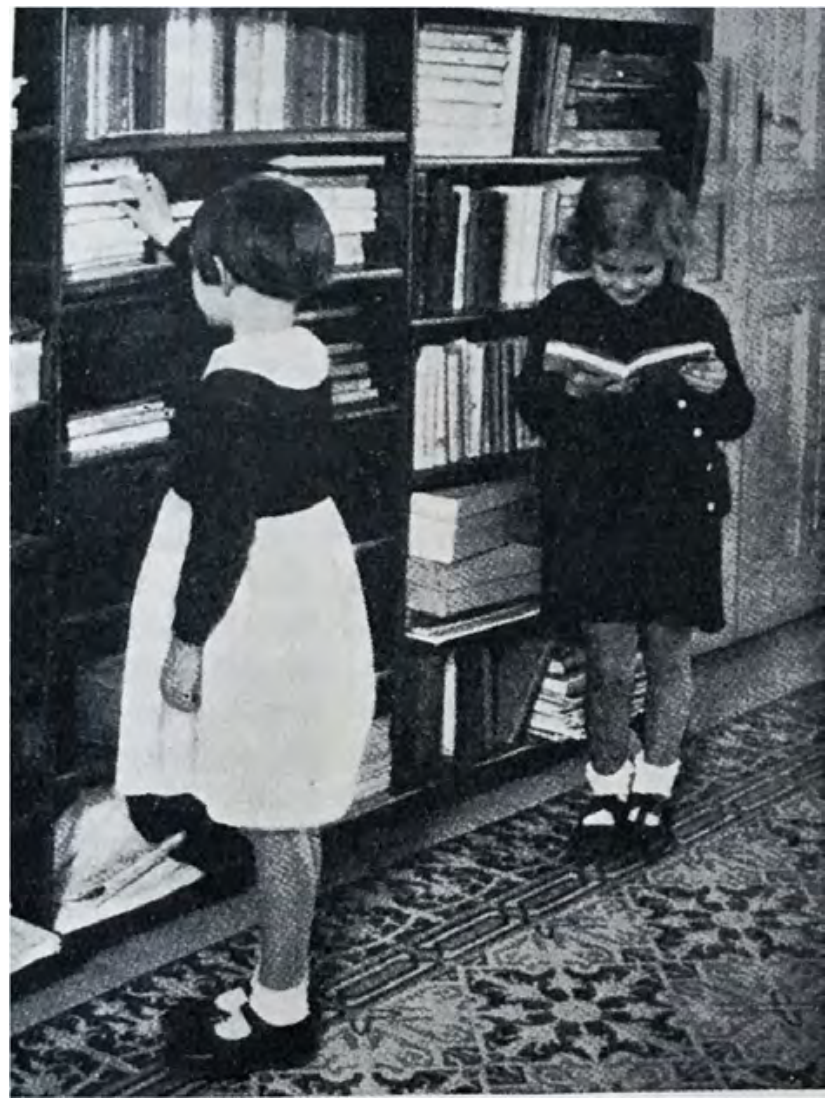

Imagen 12. Ejemplo de representación de individualización. La Escuela Plurilingüe de Madrid

Fuente: «Children of the School in the Library», The New Era 16, no. 4 (1935): 95.

\footnotetext{
${ }_{53}^{5}$ José Castillejo, «Modern Languages in an International School», The New Era in Home and School 14, no. 1 (1933): 10.
} 


\section{CONCLUSIONES}

En este artículo nos planteamos estudiar el discurso visual que concibió la revista The New Era para divulgar, propagar o popularizar los principios de la Nueva Educación. Consideramos, como punto de partida, que aquellas ideas y prácticas escolares que la revista visibilizó más —es decir, de las que publicó más imágenes— fueron aquellas con las que pretendía construir en la opinión pública un imaginario de la Escuela Nueva. A través de un sistema de codificación abierta y axial, hemos categorizado los elementos observables y objetivables que aparecían en las imágenes y justificamos su relación con las ideas abstractas que querían representar, y que se identificaban con los grandes principios de la Nueva Educación. En este imaginario, el icono o la figura que la revista eligió como símbolo del movimiento fue Rabindranath Tagore, si bien el Premio Nóbel aparece como elemento central de una constelación de educadores que refuerzan el origen teosófico de la NEF. El análisis de contenido de las 944 imágenes publicadas en The New Era entre 1920 y 1939 nos permite establecer las siguientes conclusiones:

1) El corpus pedagógico que la revista transmitió de la Escuela Nueva tuvo un elemento central: la idea de actividad. El mensaje que se intentó comunicar a las audiencias era que en las escuelas del movimiento los niños trabajaban, y mucho, si bien sus ocupaciones formaban parte de un currículum novedoso compuesto principalmente por arts \& crafts, por actividades físicas, manuales, creativas, artísticas y expresivas.

2) La segunda idea clave era el paidocentrismo, el niño como centro del proceso de enseñanza-aprendizaje, simbolizado por la desaparición en las imágenes del docente o su ubicación en una posición tangencial. Esta es una iconografía absolutamente dominante, lo que demuestra y refuerza la conclusión expuesta en trabajos previos de otros autores, de que la imagen más característica de la Escuela Nueva es el maestro ausente, mientras que los alumnos aparecen inmersos en ocupaciones que parecen haber elegido de forma espontánea.

3) Aunque la Escuela Nueva propagó en muchas ocasiones esa idea de espontaneidad, de que los niños realizaban de forma autónoma las tareas que más les interesaban y que, por ello, eran mucho más felices, 
no se encuentran muchas caras sonrientes en las fotografías. Los gestos y posiciones son muy relajados, pero las expresiones faciales son más bien serias, similares a las que se encuentran en las imágenes de la escuela tradicional, si bien es posible que esto se deba a las limitaciones de la técnica fotográfica en aquellos años. ${ }^{54}$

4) El discurso visual de The New Era demuestra que una de las ideas más difíciles de representar y de comunicar al público fue la de libertad. Su posible objetivación en la desnudez de los cuerpos claramente no se utilizó como elemento propagandístico; es un tema iconográfico absolutamente excepcional y las pocas fotografías que se publicaron fueron justificadas en el pie por la expresión «ola de calor». Está claro que la revista consideró que esa imagen no tendría el mismo significado dentro de los círculos de la NEF que ante las grandes audiencias, para las que la visión de niños desnudos ya no se identificaba con el discurso de la inocencia propio de la Ilustración, sino que empezaba a ligarse al nuevo discurso freudiano sobre la sexualidad infantil y, por tanto, despertaba indignación y escándalo.

5) La coeducación fue otro de los buques insignia del movimiento, una de sus señas más claras de identificación. En más de la mitad de fotografías publicadas en las que aparecen niños, se muestra a los dos sexos realizando actividades conjuntas. Pero el porcentaje de imágenes en las que varones y hembras trabajaban por separado siguió siendo elevado, lo cual nos indica que la coeducación no era una práctica universal en la Escuela Nueva, ni tampoco se quería presentar como la única posible.

6) El principio de la educación en contacto con la naturaleza también está presente en las fotografías de The New Era, aunque siguieron predominando las escenas dentro de los muros de la escuela. Sin embargo, ésta es la iconografía que rompe más claramente con la escenografía de la escuela tradicional, cambiando el paisaje en el que habitualmente se desarrollaban las actividades educativas. Aunque en muchas ocasiones parece que se haya modificado sólo el decorado, el attrezzo sigue siendo el mismo; por ejemplo, es relativamente frecuente encontrar clases al

\footnotetext{
${ }^{54}$ Sjaak Braster, «The progressive child: Images of new education in the New Era, 1920-1939», History of Education \& Children Literature 13, no. 1 (2018) (en prensa).
} 
aire libre en las que bancos y pizarras salieron al exterior para reproducir una coreografía propia de la escuela tradicional.

7) La revista resolvió las tensiones entre la individualización y la socialización decantándose a favor de esta última incluso desde sus primeros momentos. La idea de la expresión creativa del niño sólo se manifestó con cierta fuerza entre 1920 y 1924, y se hizo visible exclusivamente a través de las producciones artísticas infantiles. Esta es una conclusión sorprendente, pues la mayoría de sus editores teósofos creían en la liberación de las fuerzas espirituales del niño y algunos de sus redactores, como Claude Claremont o A. J. Lynch, realizaron en sus escuelas experiencias muy conocidas de individualización. Se percibe incluso una contradicción entre textos e imágenes; en la década de los años veinte abundaron los artículos sobre el método Montessori y el Plan Dalton, considerados como individualizados, pero las imágenes que se publicaron mostraron aulas de clase en las que se practicaba el método de proyectos. Una posible explicación a esta contradicción es que la iconografía de la individualización se acercaba bastante a la de la escuela tradicional, al igual que muchas de sus prácticas escolares, por lo que no ofrecía una buena imagen propagandística de las ideas de la Nueva Educación. Tampoco lo era Montessori, cuestionada duramente en el mundo anglosajón por su espíritu mercantilista y casi olvidada ya en Estados Unidos.

En los años treinta el cambio de orientación de la NEF hacia la defensa de los valores pacifistas e internacionalistas fue muy visible, tanto en los discursos como en la temática de los congresos o en la publicidad que sus revistas hicieron de todas las escuelas europeas etiquetadas como «internacionales». Sin embargo, este discurso apenas aparece en las imágenes; es muy difícil descubrir fotografías que representen estos nuevos valores. Quizás la crisis económica obligó a abaratar los costes de The New Era y se recortó el material gráfico, que, desde luego, fue mucho más escaso a partir de 1935. Pero también es muy posible que los editores no encontraran imágenes para ilustrar sus cada vez más numerosos artículos apelando a la paz y a la concordia mundial. ¿Cómo se podía representar la paz en una Europa que se preparaba para la guerra? 


\section{Nota sobre los autores}

SJAAK BRASTER es profesor titular de Sociología y Metodología de la Investigación en la Erasmus School of Social and Behavioural Sciences, Universidad Erasmus de Rotterdam (Países Bajos). Es profesor emérito de la Universidad de Utrecht, en la que fue catedrático de Historia de la Educación y Política Educativa desde 2003 hasta 2010. Fue también Presidente de la Sección de Política Educativa de la Sociedad Holandesa de Investigación Educativa (VOR). Sus líneas de investigación son sociología de la educación y política educativa; análisis de nuevas fuentes y exploración de nuevas metodologías en Historia de la Educación. Algunos de sus libros son: De identiteit van het openbaar onderwijs (Groningen: Wolters-Noordhof, 1996), De kern van casestudy's (Assen: van Gorcum, 2000), De Onderwijsraad en de herziening van het adviesstelsel (Den Haag: Onderwijsraad, 2004), The Black Box of Schooling. A Cultural History of the Classroom (Brussels: Peter Lang, 2011) (con Ian Grosvenor y María del Mar del Pozo Andrés) y A History of Popular Education: Educating the People of the World (New York: Routledge, 2013) (con Frank Simon e y Ian Grosvenor). Sus artículos más recientes son: «Choice and competition in education: Do they advance performance, voice and equality?» (con Peter Mascini, en Public Administration, 2017), "The Dalton Plan in Spain: reception and appropriation (1920-1939)» (con María del Mar del Pozo Andrés, en Revista de Educación, 2017) y "Regional ethnic diversity, school ethnic diversity, and PISA performance across Europe» (con Jaap Dronkers, en Louis Volante (ed.), The PISA effect on global educational governance, New York: Routledge, 2017).

María del Mar del Pozo Andrés es catedrática de Teoría e Historia de la Educación en la Universidad de Alcalá. Es licenciada y doctora en Filosofía y Ciencias de la Educación, con Premio Extraordinario Fin de Carrera, Premio Extraordinario de Doctorado y Mención Honorífica en la modalidad de Tesis Doctorales en los Premios Nacionales a la Investigación Educativa 1996.

Sus líneas de investigación son: historia de la educación urbana, formación inicial y permanente del profesorado, historia de las innovaciones educativas y de los movimientos de renovación pedagógica, recepción y transferencia de las corrientes educativas internacionales, el papel de la educación en la construcción de identidades nacionales, iconografía y educación, educa- 
ción y género y cultura escolar. Entre sus publicaciones más recientes se incluyen las siguientes: edición del monográfico «El sistema educativo español: viejos problemas, nuevas miradas. Conmemoración de un bicentenario (1813-2013)», Bordón. Revista de Pedagogía 65, no. 4 (2013); Justa Freire o la pasión de educar: Biografía de una maestra atrapada en la historia de España (1896-1965) (Barcelona: Octaedro, 2013) e "Images of the European Child», número monográfico de History of Education \& Children's Literature XIII, no. 1 (2018) (en colaboración con Bernat Sureda García). Ha sido la coordinadora del Proyecto de I+D MIRADAS (2015-2017), titulado «Renovación y tradición escolar en España a través de la fotografía (1900-1970)», financiado por el Ministerio de Economía y Competitividad.

Ha sido miembro del Comité Ejecutivo de la International Standing Conference for the History of Education (2006-2012), Secretaria General de la Sociedad Española de Pedagogía (2000-2006) y Secretaria de la Sociedad Española de Historia de la Educación (2005-2013). Desde 2014 es uno de los cuatro editores de Paedagogica Historica. International Journal of the History of Education.

\section{REFERENCIAS}

ALDRICH, Richard. «The Plowden report, 1967: A visual study in primary school location, space and learning». Comunicación presentada en ISCHE XX, Universidad de Lovaina, Bélgica, 1998.

Altamira, Rafael. Exigencias de la propaganda pedagógica. Madrid: Tipografía «La Itálica», 1913.

Archer, Margaret S. Social origins of educational systems. London/New York: Routledge, 2013.

BELL, Philip. «Content analysis of visual images». En Handbook of visual analysis, editado por Theo Van Leeuwen y Carey Jewitt, 10-34. London: Sage, 2001.

Bernays, Edgard L. Propaganda. New York: Horace Liveright, 1928.

Bock, Annekatrin, Holger IsERman y Thomas KNIEPER. "Quantitative content analysis of the visual». En The Sage Handbook of visual research methods, editado por Eric Margolis y Luc Pauwels, 265-282. London: Sage, 2011.

Braster, Sjaak. "Educational change and Dutch classroom photographs: A qualitative and quantitative analysis». En The Black Box of Schooling. A Cultural History of the Classroom, editado por Sjaak Braster, Ian Grosvenor y María del Mar del Pozo Andrés, 21-37. Brussels: Peter Lang, 2011. 
Braster, Sjaak y María del Mar del Pozo Andrés. «Education and the children`s colonies in the Spanish Civil War (1936-1939): the images of the community ideal». Paedagogica Historica 51, no. 4 (2015): 455-477.

BRASTER, Sjaak. "The progressive child: Images of new education in the New Era, 1920-1939». History of Education \& Children Literature 13, no. 1 (2018) (en prensa).

Brehony, Kevin J. «From the particular to the general, the continuous to the discontinuous: progressive education revisited». History of Education 30, no. 5 (2001): 413-432.

- «A New Education for a New Era: The Contribution of the Conferences of the New Education Fellowship to the Disciplinary Field of Education 19211938». Paedagogica Historica 40, no. 5-6 (2004): 733-755.

Burke, Catherine y Ian Grosvenor. "The Progressive Image in the History of Education: Stories of Two Schools». Visual Studies 22, no. 2 (2007): 155168.

Burke, Catherine. «Feet, footwork, footwear, and "being alive" in the modern school». Paedagogica Historica 54, no. 1-2 (2018): 32-47.

Collins, Michael. «History and the Postcolonial. Rabindranath Tagore's Reception in London, 1912-1913». The International Journal of the Humanities 4, no. 9 (2007), 71-83.

Comas Rubí, Francisca y Bernat Sureda García. «The photography and propaganda of the Maria Montessori method in Spain (1911-1931)». Paedagogica Historica 48, no. 4 (2012): 571-587.

Condette, Jean-François y Antoine SAVoye. «Une éducation pour l'ère nouvelle, le congrès international d'éducation de Calais 1921». Études Sociales 163 (2016): 43-79.

Coquoz, Joseph. «Un modèle suisse “d'École active” durant l'entre-deux-guerres: images et mirages». Paedagogica Historica 36, no. 1 (2000): 369-388.

Di Franco, Giovanni. «Multiple correspondance analysis: one only or several techniques?». Quality \& Quantity. International Journal of Methodology 50, no. 3 (2016): 1299-1315.

FAllace, Thomas. "The Savage Origins of Child-Centered Pedagogy, 18711913». American Educational Research Journal 52, no. 1 (2015): 73-103.

FucHs, Eckhardt. «Educational sciences, morality and politics. International educational congresses in the early twentieth century». Paedagogica Historica 40, no. 5-6 (2004): 757-784.

Gutek, Gerald L., y Patricia A. Gutek. Bringing Montessori to America. S.S. McClure, Maria Montessori and the Campaign to Publicize Montessori Education. Tuscaloosa: The University of Alabama Press, 2016. 
Gutierrez, Laurent. «La Ligue Internationale pour l'Éducation Nouvelle. Contribution à l'histoire d'un mouvement international de réforme de l'enseignement (1921-1939)». Spirale - Revue de Recherches en Éducation 45 (2009): 29-41.

Haenggeli-Jenni, Béatrice. «Pour l'Ėre Nouvelle: une revue carrefour entre science et militance (1922-1940)». PhD diss., Universidad de Ginebra, 2011.

- "Savoirs" constitués et programmes scolaires: débats au cœur de la revue Pour l'Ère Nouvelle (1922-1940)». Recherches \& Éducations 4 (2011): 13-25.

Haenggeli-Jenni, Béatrice y Rita Hofstetter. "Pour l'Ėre Nouvelle (1922-1940). La science convoquée pour fonder une "Internationale de l'Éducation"». Carrefours de l'Éducation 31 (2011): 137-159.

Hameline, Daniel. «Les premières années de Pour l'Ėre nouvelle: militantisme et propagande?». Les Sciences de l'éducation - Pour l'Ère nouvelle 35, no. 4 (2002): 27-40.

Haubfleisch, Dietmar y Jörg-Werner Link (eds.). Das Werdende Zeitalter (Internationale Erziehungs-Rundschau). Bonn: Archiv der Arbeiterjugendbewegung, 1994.

Huntley, Herbert E. The divine proportion. A study in mathematical beauty. New York: Dover Publications, 1970.

JENKIns, Celia M. «The professional middle class and the social origins of progressivism: A case study of the New Education Fellowship, 1920-1950». PhD diss., Universidad de Londres, 1989.

— «New Education and its emancipatory interests (1920-1950)». History of Education 29, no 2 (2000): 139-151.

KING, Alison. «From sage on the stage to guide on the side». College Teaching 41, no. 1 (1993): 30-35.

Koslowski, Steffi. Die New Era der New Education Fellowship: Ihr Beitrag zur Internationalität der Reformpädagogik in 20. Jahrhundert. Bad Heilbrunn: Julius Klinkhardt, 2013.

KrIPPEndorf, Klaus. Content analysis: An introduction to its methodology. London: Sage, 2004.

LABRA, Rafael María de. Discurso pronunciado el día 11 de noviembre de 1913 en el Ateneo de Madrid, con motivo de la apertura de las Cátedras. Madrid: Est. Tip. de Fortanet, 1913.

LAQUA, Daniel. «Transnational intellectual cooperation, the League of Nations, and the problem of order». Journal of Global History 6, no. 2 (2011): 223247.

Lawson, Maxwell D. «The New Education Fellowship: The Formative Years». Journal of Educational Administration and History 13, no. 2 (1981): 24-28. 
Lubelsky, Isaac. Celestial India: Madame Blavatsky and the Birth of Indian Nationalism. Oakville, CT: Equinox Publication, 2012.

Middleton, Sue C. "New Zealand Theosophists in "New Education" networks, 1880s-1938». History of Education Review 46, no. 1 (2017): 42-57.

Moore, Colin. Propaganda Prints. A History of Art in the Service of Social and Political Change. London: A\&C Black Publishers Limited, 2010.

Mukhopadhyay, Mriganka. «The Occult and the Orient. The Theosophical Society and the Socio-Religious Space in Colonial India». Presidency Historical Review 1, no. 2 (2015): 9-37.

Newcourt-Nowodworski, Stanley. La propaganda negra en la Segunda Guerra Mundial. Barcelona: Algaba Ediciones, 2006.

OelKers, Jürgen. Reformpädagogik: Eine kritische Dogmengeschichte. Weinheim: Juventa, $2005^{4}$.

Ploeg, Piet van der. Dalton Plan: Origins and Theory of Dalton Education. Deventer: Saxion Dalton University Press, 2013.

- «The Dalton Plan: recycling in the guise of innovation». Paedagogica Historica 49, no. 3 (2013): 314-329.

Pozo ANDrés, María del Mar del. «La imagen de la mujer en la educación contemporánea». En Las mujeres en la construcción del mundo contemporáneo, editado por Teresa Marín Eced y María del Mar del Pozo Andrés, 241-301. Cuenca: Diputación de Cuenca, 2002.

- «Imágenes e historia de la educación: construcción, reconstrucción y representación de las prácticas escolares en el aula». Historia de la Educación. Revista Interuniversitaria 25 (2006): 291-315.

- "The transnational and national dimensions of pedagogical ideas: the case of the project method, 1918-1939». Paedagogica Historica 45, no 4-5 (2009): 561-584.

Pozo Andrés, María del Mar del y Sjaak Braster. «El Plan Dalton en España: Recepción y Apropiación (1920-1939)». Revista de Educación 377 (2017): 113-135.

RiondET, Xavier. «Élise Freinet: de l'expérience naturiste aux pratiques de l'École Freinet». Recherches \& éducations [En abierto], 8 Juin 2013, document 9, mis en ligne le 15 juillet 2013, consultado el 11 enero 2018.

Rose, Gillian. Visual methodologies: An introduction to researching with visual materials. London: Sage, $2016^{4}$.

Selten, Marjolein y Fleur van der Zandt. «Space vs. Place». http:/geography. ruhosting.nl/geography/index.php?title=Space_vs._place (consultado el 3112-2017).

Strauss, Anselm y Juliet M. Corbin. «Grounded theory methodology: An overview». En Handbook of qualitative research, editado por Norman K. Denzin e Yvonna S. Lincoln, 273-285. Thousand Oaks: Sage, 1994. 
VAN GoRP, Angelo. «The Decroly School in documentaries (1930s-1950s): contextualising propaganda from within». Paedagogica Historica 47, no. 4 (2011): 507-523.

WAGNER, Peter. Reading Iconotexts. From Swift to the French Revolution. London: Reaktion Books, 1995.

WAGNON, Sylvain. «Les théosophes et l'organisation internationale de l'éducation nouvelle (1911-1921)». REHMLAC+ 9, no. 1 (2017): 146-180.

Watras, Joseph. "The New Education Fellowship and UNESCO's programme of fundamental education». Paedagogica Historica 47, no. 1-2 (2011): 191205.

White, Margaret H. «The New Education Fellowship: An international community of practice». New Era in Education 82, no. 3 (2001): 71-75. 